\title{
APPLICATION OF MULTIPLE CRITERIA DECISION MAKING METHODS IN CONSTRUCTION: A SYSTEMATIC LITERATURE REVIEW
}

\author{
Xingyu ZHU®1, Xianhai MENG ${ }^{\circledR 1}{ }^{*}$, Min ZHANG®2 \\ ${ }^{1}$ School of Natural and Built Environment, Queen's University Belfast, Belfast, BT9 5AG, UK \\ ${ }^{2}$ Queen's Management School, Queen's University Belfast, Belfast, BT9 5EE, UK
}

Received 21 December 2019; accepted 15 April 2021

\begin{abstract}
Decision making is a key to business or project success in any sectors, especially in construction that requires handling numerous information and knowledge. Multiple criteria decision making (MCDM) is an important tool for decision problem solving due to simultaneous consideration of multiple criteria and objectives. Various MCDM methods are continually emerging and tend to be increasingly adopted to address the real-world construction problems. Therefore, it is urged to systematically review the existing body of literature to demonstrate the evolution of the mainstream MCDM methods in general and their application status in construction. A total of 530 construction articles published from 2000 to 2019 are selected in this study and then categorized into seven major application areas using a novel systematic literature review (SLR) methodology. The bibliometric analysis is then used to describe the research trend. Subsequently, the qualitative discussion by themes is conducted to analyze the application of MCDM methods in construction. A further discussion makes it possible to identify the potential challenges (e.g. applicability, robustness, postpone effect, dynamic and prospective challenges and scale problem) to existing research. It also contributes to the recommendation of future directions for the development of MCDM methods that would benefit construction research and practice.
\end{abstract}

Keywords: decision support system, construction, multiple criteria decision making, multiple attribute decision making, multiple objective decision making, systematic literature review.

\section{Introduction}

The significant role of construction in economic development has been widely acknowledged and long recognized (Giang \& Pheng, 2011; Zhao et al., 2012). Construction activities can often be described as a summary of various tasks and requirements, involving conflicting aspects and factors to consider (Jato-Espino et al., 2014). Due to the sophistication of technologies and the increase in complexity and dynamics, decision making in construction projects is becoming complicated and difficult (de Azevedo et al., 2013; Bakht \& El-Diraby, 2015). Therefore, accurate and agile decisions should be made in a scientific manner based on qualitative or quantitative analysis (Zavadskas et al., 2016a), rather than relying solely on intuition or experience. Otherwise, there may be a latent negative effect on resource utilization, cost efficiency, environment and sustainability (Sitorus et al., 2019).

Based on theoretical and practical requirements, a wide variety of MCDM methods have been developed in general
(Zavadskas et al., 2016b), with even minor variations or a combination of existing methods to create new branches of relevant research (Velasquez \& Hester, 2013). This may favor decision makers in providing more choices, but appear to be a paradoxical result, as selecting an appropriate method among various alternatives may be difficult, particularly for decision makers with a limited understanding of MCDM methods. As an operational research method comprehensively considering computational and mathematical tools in a certain environment to find a suitable solution (Zavadskas et al., 2014), MCDM has attracted considerable academic attention across a number of industry sectors. Due to the complex and dynamic nature, the above-mentioned problem is particularly true for the use of MCDM methods in the construction industry and its projects. Therefore, this paper addresses the problem through a thorough investigation of existing MCDM methods and a systematic synthesis of their application in construction.

${ }^{*}$ Corresponding author. E-mail: x.meng@qub.ac.uk 
Actually, several previous attempts have been made to review the literature on the use of MCDM methods in construction. For example, Jato-Espino et al. (2014) evaluated the application of six MCDM methods and their hybrid variants in construction. Sierra et al. (2018) reviewed the state-of-the-art of 19 multiple-criteria assessment methods for social sustainability in infrastructure development. Despite that, some limitations exist within these previous literature reviews. Firstly, only a limited number of MCDM methods are discussed, ignoring the differences and connections among various MCDM methods. Secondly, the majority of these literature reviews are not strictly conducted in a systematic manner, yielding results that are supposedly affected by bias. Thirdly, some literature reviews are based on different MCDM methods instead of their application areas, which tend to be method-oriented rather than problem-oriented.

This research aims to systematically review the application status of MCDM methods in the construction industry. The specific objectives of this research are: (1) to classify MCDM methods in general and analyze their relationships; (2) to identify the evolution of MCDM methods; (3) to design a novel methodology for systematically reviewing the utilization of MCDM models in construction from the bibliometric perspective; (4) to determine the main areas of applying MCDM models in construction; and (5) to analyze the potential gaps and provide future directions for MCDM research in construction. The following sections are arranged accordingly to achieve the research objectives one by one.

\section{Overview of MCDM methods}

\subsection{Concept and general structure of MCDM}

Although MCDM methods are widely diverse, how to evaluate a set of alternatives in terms of a number of criteria is a key issue of MCDM methods in general (Triantaphyllou, 2000). MCDM refers to making decisions in the presence of multiple, usually conflicting criteria (Zavadskas et al., 2014). It can be perceived as a process of evaluating the real-world situations based on various qualitative and/or quantitative criteria in certain circumstances to find a suitable alternative/solution. Roy (1996) defined four types of problems that MCDM can solve: (1) selection problem, in which MCDM is adopted to choose a specific alternative or develop a selection procedure; (2) sorting problem, in which MCDM is used to assign the alternatives in terms of norms or build the assignment procedure; (3) ranking problem, in which MCDM is applied to order the alternatives according to the preference or set up the ranking procedure; and (4) description problem, in which MCDM is utilized to present the alternatives and their consequences. The problem structure of MCDM is treated as a combination of problems and methods (Keeney, 1982; Cinelli et al., 2014). From this perspective, the whole MCDM process can be divided into four stages, namely problem structuring, problem formulating, method selection and evaluation, and decision recommendation (Bouyssou et al., 2006; Tsoukiàs, 2007; Bigaret et al., 2017).

\subsection{Classification of MCDM}

MCDM consists of many subfields. Existing studies show that MCDM can mainly be divided into multiple attribute decision making (MADM) and multiple objective decision making (MODM) (Hwang \& Yoon, 1981; Chen \& Hwang, 1992; Zavadskas et al., 2014; Kahraman \& Otay, 2019). According to Hwang and Masud (1979), the distinctive feature of MADM is that there are usually a limited number of predetermined alternatives. The selection of alternatives is based on inter- and intra-attribute comparisons, which involve explicit or implicit trade-offs. On the contrary, the alternatives of MODM are not predetermined. MODM methods are to design the alternatives in terms of their constraints to attain the acceptable levels of objectives. Triantaphyllou (2000) concluded that MADM concentrates on discrete decision spaces, whereas MODM studies decision problems whose space is continuous.

\subsection{Evolutionary development of MADM}

The historical origin of MADM can be traced back to the research on utility theory published by Bernoulli in 1738 . According to Bernoulli (1738), a decision is made on the basis of the utility value rather than the excepted value. von Neumann and Morgenstern (1947) further paved the way for the development of MADM by applying the dynamic mathematic model for strategic interaction between rational decision makers. Nowadays, MADM methods are generally grouped into six categories, including multiple attribute utility (value) functions, pairwise comparisons methods, distance (ratio) to reference point methods, outranking-based MADM methods, fuzzy set methods and their variants, and other MADM methods. Based on Liou and Tzeng (2012) and Tzeng and Shen (2017), this research summarizes the evolutionary development of MADM methods in the form of dendrogram (see Figure 1). The six categories of MADM are discussed below one by one.

\subsubsection{Multiple attribute utility (value) functions}

The goal of multiple attribute utility (value) functions is to construct the expression that represents the preference of decision makers based on utility/value functions. Although utility/value functions can be utilized to transform the values of diverse criteria for alternatives, either factual (objective, quantitative) or judgmental (subjective, qualitative), into a common and dimensionless scale (Fülöp, 2001), an obvious drawback of utility/value functions is that the criteria should follow the assumption of independence, which is termed preferential independence. As a result, Choquet (1954) and Sugeno (1974) proposed Choquet integral and Sugeno integral, respectively, to address the interrelationship among the criteria (Angilella et al., 2004). Representative methods in this category include simple additive weighting (SAW) (value added not utility) by MacCrimmon (1968) and multi-attribute utility theory (MAUT) by Keeney and Raiffa (1972) and 


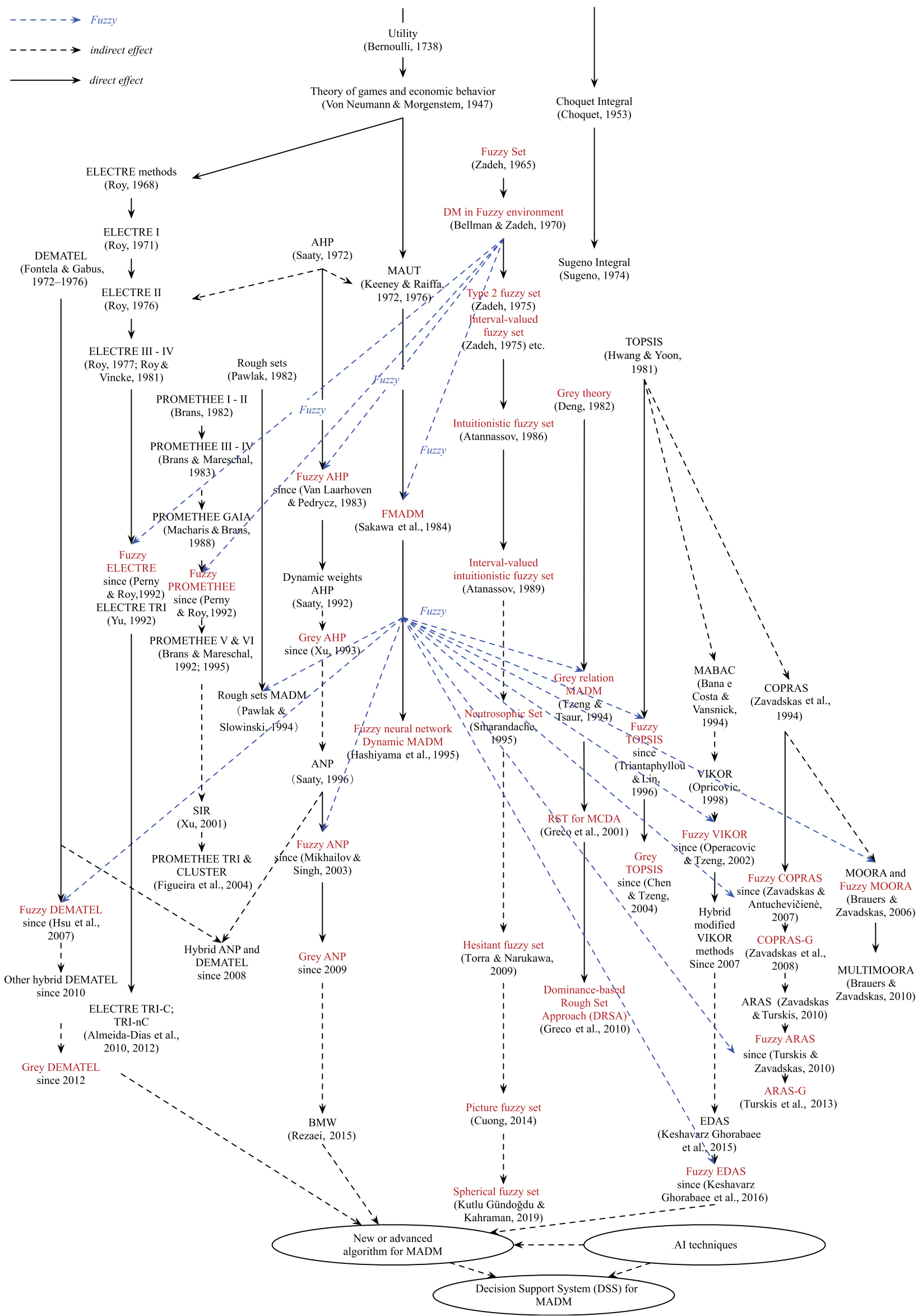

Figure 1. Evolutionary development of MADM methods 
Keeney and Raiffa (1976). In addition to MAUT, Edwards (1971) developed simple multi-attribute rating technique (SMART) for multi-attribute utility measurement. SMART was further corrected by Edwards and Barron (1994) and renamed to SMART using swings (SMARTS). SMART and SMARTS are two simplest MAUT methods (Chen et al., 2010).

The weights of the criteria play a critical role in the methods of this category and have an influence on the process of evaluation. Several studies have been conducted for weights calculation. Keršulienè et al. (2010) suggested a new step-wise weight assessment ratio analysis (SWARA) technique for the determination of attributes' weights and provided an opportunity to estimate the differences of their significances. Ginevičius (2011) offered factor relationship (FARE) to measure the weights based on the relationships between all the criteria describing the phenomenon considered. Krylovas et al. (2014) proposed the Kemeny median indicator ranks accordance (KEMIRA) method to determine criteria priority and select criteria weights in the case of two separate groups of criteria. To address the impreciseness of criteria measurement, Jessop (2014) presented imprecise multi-attribute evaluation (IMP) to describe the weights by a suitable probability distribution. Zavadskas and Podvezko (2016) supported integrated determination of objective criteria weights (IDOCRIW) that combines the weights yielded by the entropy and the criterion impact LOSs (CILOS) method. These weighting methods can also be adopted in the following MCDM methods that involve the weights of criteria.

\subsubsection{Pairwise comparisons methods}

Analytic hierarchy process (AHP) was designed by Saaty (1972), streamlining a complex problem into a hierarchy structure and eliciting the preference by converting the subjective comparison of relative importance into the overall scores or weights. Due to the limitation of independence assumption of criteria for AHP, its extension method analytic network process (ANP) includes the interrelationships among criteria (Saaty, 1996). A wide criticism received is that AHP and ANP over-rely on the subjective opinions of experts or decision makers. Dynamic AHP (DAHP) developed by Saaty (1992) can solve the inconsistency of expert opinions to some extent. Moreover, the impreciseness of expert opinions should be considered. To reduce the comparison data in AHP and ANP, Rezaei (2015) proposed the best-worst method (BWM) to derive the weights based on a pairwise comparison of the best and the worst criteria/alternatives with other criteria/ alternatives. The result reveals that BWM is more easily used and performs better compared to AHP and ANP.

\subsubsection{Distance (ratio) to reference point methods}

Distance to reference point methods include technique for order preference by similarity to an ideal solution (TOPSIS) (Hwang \& Yoon, 1981), complex proportional assess- ment (COPRAS) (Zavadskas et al., 1994), multi-attribute border approximation area comparison (MABAC) (Bana e Costa \& Vansnick, 1994), Vlsekriterijumska optimizacija i kompromisno resenje (VIKOR) (Opricovic, 1998), multiobjective optimization by ratio analysis (MOORA) (Brauers \& Zavadskas, 2006), MOORA plus full multiplicative form (MULTIMOORA) (Brauers \& Zavadskas, 2010), additive ratio assessment (ARAS) (Zavadskas \& Turskis, 2010), and evaluation based on distance from average solution (EDAS) (Keshavarz Ghorabaee et al., 2015). All these methods are based on the aggregation function that represents the degree of proximity with the reference point to determine the preference. In this process, normalization is adopted to eliminate the units and scale of criteria, and the weights of the criteria can be generated by different methods, such as the weighting methods mentioned in Sections 1.3.1 and 1.3.2.

The best (compromise) alternative of TOPSIS should have the shortest distance from the positive ideal point and the longest distance from the negative ideal point. MABAC ranks the alternatives according to the distance to the border approximation area. As for VIKOR, the best alternative provides a maximum utility of the majority and a minimum of an individual regret. EDAS chooses the best alternative relating to the distance from average solution. COPRAS determines the ranking of alternatives by the calculated utility ratio based on the minimization index and the maximization index. MOORA ranks the alternatives based on the distance with the ratio, which is representative for all alternatives concerning that objective. MULTIMOORA further orders the utility function of alternatives according to the ratio of the product of maximizing attributes' values to the product of minimizing attributes' values. And ARAS ranks the alternatives based on the utility degree calculated by comparison with the ideally best optimality function.

\subsubsection{Outranking-based MADM methods}

Unlike MCDM methods that assume the existence of a single optimal alternative, outranking-based MADM methods follow the principle that one alternative may have a degree of dominance over another (Kangas et al., 2001). As a member in this category, elimination et coix traduisant la realité (ELECTRE) is a family that provides a series of methods (Roy, 1968). ELECTRE I (Roy, 1971) is designed for the selection problem. ELECTRE II (Roy, 1976), ELECTRE III (Roy, 1977) and ELECTRE IV (Roy \& Vincke, 1981) characterize the ranking problem by ordering alternatives from the best to the worst. ELECTRE TRI (Yu, 1992), ELECTRE TRI-C (Almeida-Dias et al., 2010) and ELECTRE TRI-nC (Almeida-Dias et al., 2012) tackle the sorting problem by assigning alternatives to predefined sets (Govindan \& Jepsen, 2016).

Preference ranking organization method for enrichment evaluation (PROMETHEE) is another family member in this category, which deals with "the appraisal and the selection of a set of options on the basis of several criteria, with the objective of identifying the pros and 
cons of the alternatives and obtaining a ranking among them" (Cascales et al., 2015). Brans (1982) developed PROMETHEE I for partial ranking and PROMETHEE II for complete ranking. Soon thereafter, PROMETHEE III and PROMETHEE IV were proposed for interval order and continuous case, respectively. Two extension methods were PROMETHEE $\mathrm{V}$ involving the segmentation constraints (Brans \& Mareschal, 1992) and PROMETHEE VI representing the human brain (Brans \& Mareschal, 1995). Moreover, Figueira et al. (2004) put forwarded two new methods, namely PROMETHEE TRI for dealing with the sorting problem and PROMETHEE CLUSTER for addressing the nominal classification. Similar to PROMETHEE methods, Xu (2001) introduced superiority and inferiority ranking (SIR) method that is based on the utilization of superiority and inferiority values to determine the type of the preference function.

\subsubsection{Fuzzy set methods and their variants}

For the purpose of dealing with uncertain information, Zadeh (1965) and Bellman and Zadeh (1970) put forward fuzzy set theory (generally Type-1 fuzzy set), which is characterized by a membership function that represents the degree of truth in fuzzy logic. It was generalized by Zadeh (1975) through proposing Type-2 fuzzy set that incorporates uncertainty into the membership function of a fuzzy set. As a special case of Type-2 fuzzy set, intervalvalued fuzzy set (IVFS) proposed by Zadeh (1975) and other researchers has attracted great attention because the membership function of interval arithmetic is much simpler than the general Type-2 fuzzy set. Atanassov (1986) introduced intuitionistic fuzzy set (IFS) characterized by the membership degree and non-membership degree, based on which Atanassov and Gargov (1989) further defined interval-valued intuitionistic fuzzy set (IVIFS). In order to express the opinions of decision makers more realistically and accurately, Cuong (2014) proposed picture fuzzy set (PFS), including positive, neutral, negative, and refusal membership functions. As an extension of IFS, Kutlu Gündoğdu and Kahraman $(2019,2020)$ introduced Spherical fuzzy set (SFS) to raise the membership functions from two to three dimensions.

Sometimes, it is difficult to determine the accurate membership degree of evaluation information. For this reason, Torra and Narukawa (2009) introduced hesitant fuzzy set (HFS), in which the membership degrees are represented by several possible crisp numbers. Smarandache (1998) put forward neutrosophic set (NS) to deal with incomplete, indeterminate and inconsistent decision information through truth, falsity and indeterminacy memberships, generalizing fuzzy set theory, IFS and HFS. The corresponding membership functions of such decision information are non-standard subsets of $[0,1]^{*}$. In addition to the above-mentioned fuzzy set methods, rough set and grey set were proposed by Pawlak (1982) and Deng (1982), respectively, to solve problems in different scenarios. Compared to traditional fuzzy set that addresses subjective uncertainty, such as artificial classi- fication and language description, rough set and grey set relate to objective uncertainty, such as missing information and unpredictable process.

Among existing studies on uncertain MADM, Sakawa et al. (1984) used fuzzy MADM methods to solve nonlinear programming problems. Hashiyama et al. (1995) explored dynamic MADM methods by fuzzy neural network. In addition, a large number of pioneers are committed to combining fuzzy set with existing MADM methods, including Fuzzy-AHP (van Laarhoven \& Pedrycz, 1983), Fuzzy ELECTRE, Fuzzy PROMETHEE (Perny \& Roy, 1992), Fuzzy TOPSIS (Triantaphyllou \& Lin, 1996), Fuzzy VIKOR (Opricovic \& Tzeng, 2002), Fuzzy-ANP (Mikhailov \& Singh, 2003), Fuzzy MOORA (Brauers \& Zavadskas, 2006), Fuzzy COPRAS (Zavadskas \& Antuchevičienè, 2007), fuzzy decision making trial and evaluation laboratory (DEMATEL) (Hsu et al., 2007), Fuzzy ARAS (Turskis \& Zavadskas, 2010) and Fuzzy EDAS (Keshavarz Ghorabaee et al., 2016), etc. (see Figure 1).

With regard to rough set and grey set, Pawlak and Słowiński (1994) utilized rough set in the field of MADM. Tzeng and Tasur (1994) conducted multi-criteria evaluation of grey relation models. Greco et al. (2001) presented grey set theory while Greco et al. (2010) further proposed dominance-based rough set (DRSA) for decision making. Other examples of combining grey set with existing MADM methods include Grey AHP (Xu, 1993), Grey TOPSIS (Chen \& Tzeng, 2004), COPRAS of alternatives with grey relations (COPRAS-G) (Zavadskas et al., 2008) and ARAS with grey values (ARAS-G) (Turskis et al., 2013).

\subsubsection{Other methods}

There are many other methods that do not fall in any of hereinabove MADM categories, e.g. DEMATEL developed by Fontela and Gabus $(1972,1976)$ for the analysis of cause-effect chain components in complex structural models. To better solve complicated problems, some recent research efforts put emphasis on strengthening single methods with complement methods or replacing existing methods with advanced methods for MADM. For example, the ANP-DEMATEL hybrid can be built to develop interdependent and feedback relationships among criteria (Yang et al., 2008; Wu, 2008; Tzeng \& Shen, 2017). Modified VIKOR can be used to deal with "the best of a bad bunch" problem (Opricovic \& Tzeng, 2007). Moreover, weighted aggregated sum product assessment (WASPAS) that combines weighted sum mode (WSM) and weighted product model (WPM) significantly improve the accuracy of estimation compared to the individual use of each method (Zavadskas et al., 2012a).

\subsection{Evolutionary development of MODM}

Based on Liou and Tzeng (2012) and Tzeng and Shen (2017), Figure 2 shows the evolutionary development dendrogram of MODM methods. The concept of vector optimization proposed by Kuhn and Tucker (1951) is 


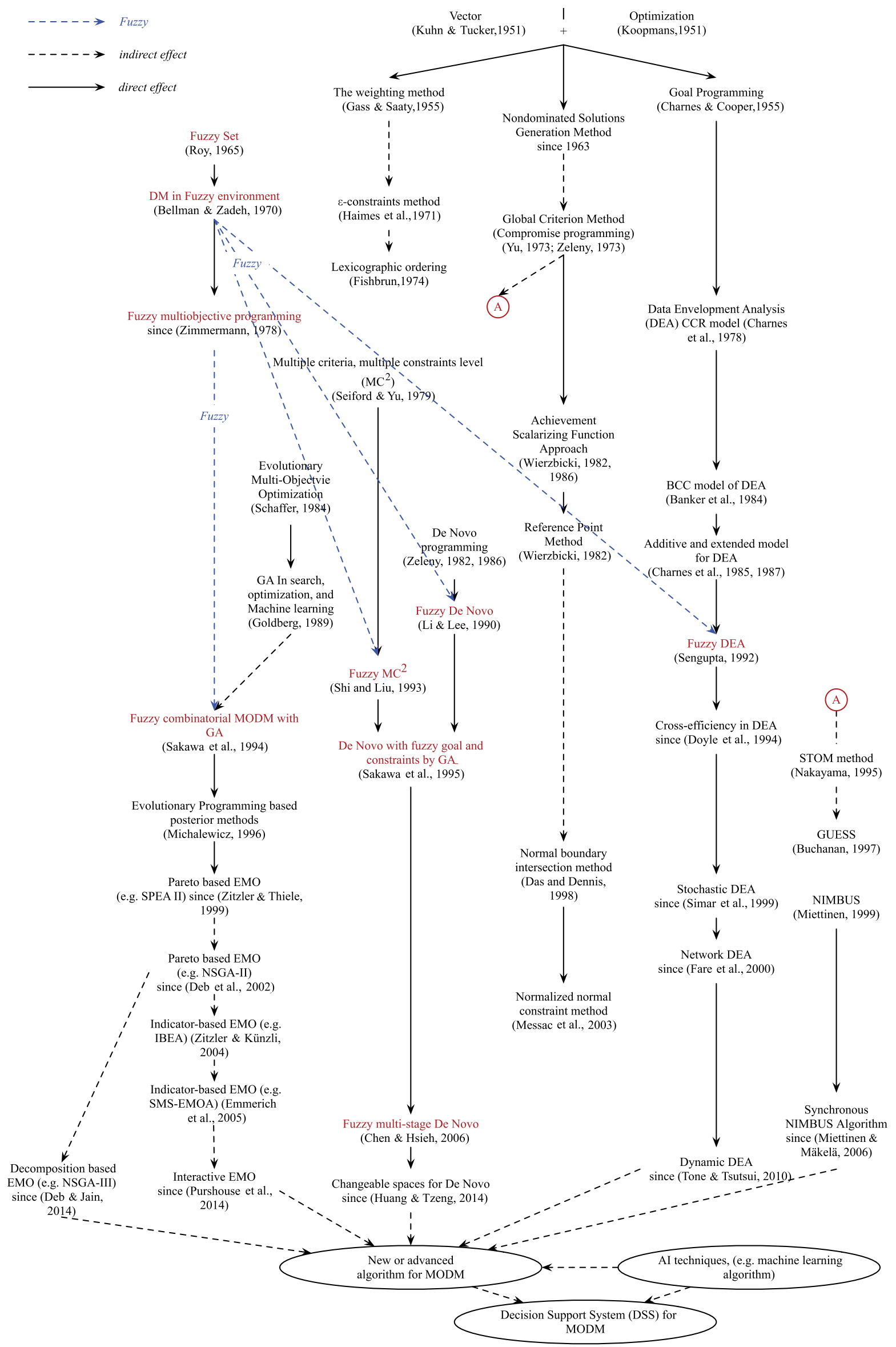

Figure 2. Evolutionary development of MODM methods 
generally recognized as the origin of MODM (Tzeng \& Shen, 2017). Most real-life MODM problems have several conflicting objectives to be considered simultaneously, which may be nonlinear. Under such circumstances, there is no single solution that optimizes the conflicting objectives, but there exist a number of Pareto-optimal solutions (Koopmans, 1951) or compromise solutions (Yu, 1973). These solutions cannot improve any objectives without deteriorating other objectives. In other words, MODM aims to solve mathematical optimization problems under specified constraints, involving more than one objective to be achieved simultaneously. Its results are a set of Paretooptimal solutions or a set of trade-offs in satisfying the conflicting objectives.

\subsubsection{No-preference methods}

MODM can be divided into methods with no-preference, methods with a priori information, methods with a posteriori information, and methods with progressive information (Cohon \& Marks, 1975; Hwang \& Masud, 1979; Sengupta et al., 2017). When using no-preference methods, the MODM problem is solved to generate some neutral compromise solutions and the preference of decision makers is not considered during the optimization process. Subsequently, decision makers can select or reject the proposed solution. Global criterion method, also known as compromise programming (Yu, 1973; Zeleny, 1973), can be regarded as the most common example in this category, whose idea is to find the closest compromise solution to the ideal objective vector. However, the challenge is that the solution varies with the change of the metrics to measure the closeness. Normalization is also required when the units and/or orders of objective functions are different.

\subsubsection{Methods with a priori information}

For methods with a priori information (namely a priori methods), decision makers provide the global preference information, such as certain desired goals or pre-ordered objectives. The Pareto-optimal solution (a close solution) is found through the scalarizing function that combines the preference information and the original problem. A priori methods include goal programming (GP) (Charnes et al., 1955), lexicographic ordering (Fishburn, 1974), etc. They deal with both ordinal and cardinal information. With regard to GP methods, decision makers specify the desired aspiration level (maximum or minimum level). GP is then used to minimize the deviations between the achievement of goals and their aspiration levels. For lexicographic ordering methods, decision makers order the objective functions based on their preference. Subsequently, the objectives are optimized until attaining the unique solution. The common weakness of a priori methods is that the preference of decision makers may be too optimistic or pessimistic. It is also hard for decision makers to express their preference without a good understanding of decision making problems.

Although data envelopment analysis (DEA) and MCDM are generally known as two different subfields of operational research and management science, they handle similar problems (Stewart, 1996). Actually, many DEA methods can be derived directly from GP (Liu \& Sharp, 1999). DEA is a mathematical programming-based method for performance evaluation where multiple inputs and outputs exist for decision making units (Cook et al., 2014). A large number of DEA methods are based on the CCR model proposed by Charnes et al. (1978). Subsequent to the CCR model, Banker et al. (1984) developed the BCC model to address the variable return to scale. Charnes et al. (1985) further introduced additive models into DEA, which was extended by Charnes et al. (1987). Sengupta (1992a, 1992b) incorporated fuzzy sets into DEA models to deal with the impreciseness or vagueness of inputs and outputs. According to Liu et al. (2016b), cross-efficiency in DEA by Doyle and Green (1994), stochastic DEA by Simar and Wilson (2000), network DEA by Fare et al. (2000), and dynamic DEA by Tone and Tsutsui (2010) represent the major schools of DEA-related research.

Traditional MODM optimization techniques focus on valuation in a fixed and given environment. However, it is usually hard to optimize all the objectives simultaneously. Thus, the trade-offs among the objectives become the key to such algorithms. Actually, the trade-offs are properties of imperfectly designed systems (Zeleny, 2011). For this reason, Zeleny $(1982,1986)$ proposed de Novo programming to enhance traditional mathematical programming by relaxing the assumption of fixed resources. As a result, the optimization trade-offs are eliminated. Among followup studies on de Novo programming, Li and Lee (1990) proposed a model of de Novo programming with fuzzy coefficients. Sasaki et al. (1995) implemented genetic algorithm (GA) for de Novo programming with fuzzy goals and constraints, which was based on multiple criteria and multiple constraints $\left(\mathrm{MC}^{2}\right)$ by Seiford and $\mathrm{Yu}(1979)$ and fuzzy $\mathrm{MC}^{2}$ by Shi and Liu (1993). Chen and Hsieh (2006) further built a fuzzy multi-stage method of de Novo programming with the dynamic nature. Huang and Tzeng (2014) extended de Novo programming to changeable space (parameters), helping decision makers to achieve the desired outcomes (aspiration levels) rather than the traditional ideal points.

\subsubsection{Methods with a posteriori information}

Methods with a posteriori information, also known as "a posteriori" methods, generate the Pareto-optimal solution and present it to decision makers for reference. Such methods deal with a single objective according to the global preference of decision makers. When using the weighting method established by Gass and Saaty (1955) in the category of a posteriori, various weight vectors can be adopted to produce Pareto-optimal solutions. Thereafter, decision makers select a most preferred solution among them. The obvious weakness of this method is that it is only suitable for convex problems and on the other hand weights are not easy to understand. Compared to the weighting method, the $\varepsilon$ constraints method proposed by Haimes et al. (1971) can be used for non-convex problems. 
It selects one of the objective functions to optimize while converting other objective functions into constraint functions by their bounds. However, there is a concern that the upper bounds are unknown before optimization and therefore have to be set properly to obtain a solution.

Based on GP, Zeleny (1973) developed the method of weighted metrics, finding different Pareto-optimal solutions closest to the ideal objective vector using metrics augmented with various weights. Through this method, decision makers can select the solution according to their preference. The achievement scalarizing function proposed by Wierzbicki $(1982,1986)$ calculates the weighted distance between the reference point and each Paretooptimal solution, based on which a new Pareto-optimal solution closest to the reference point is produced. Das and Dennis (1998) developed the normal boundary intersection (NBI) method that is independent of the relative scales of objective functions. The NBI method gives an evenly distributed set of weights to produce a uniformly distributed set of Pareto-optimal solutions, overcoming a lack of even distribution within the above-mentioned methods of weighted metrics. Compared to the NBI method, Messac et al. (2003) further designed the normalized normal constraint method to reduce the possibility of producing dominated solutions.

Evolutionary multi-objective optimization (EMO) is another a posteriori method that optimizes the complex numerical problem based on evolutionary algorithms. EMO represents a problem-independent algorithmic framework that provides a set of guidelines or strategies to explore the solution space more thoroughly and finally obtains a set of solutions that approximate the set of optimal solutions for decision makers' reference. The origin of evolutionary algorithms in MODM can be traced back to Schaffer (1984) that utilized GA for multi-objective optimization, namely vector-evaluated genetic algorithm (VEGA). Subsequently, Goldberg (1989) revolutionarily designed a new non-dominated sorting procedure, since which different EMO methods have mushroomed. Among these methods, Sakawa et al. (1994) combined fuzzy multi-objective programming by Zimmermann (1978) and EMO to deal with nonlinear goal programming. Michalewicz (1996) pointed out that evolutionary programming methods have a good performance on nonlinear constrained optimization problems.

The current EMO can be generally divided into three categories, namely Pareto based EMO, indicator-based EMO and decomposition based EMO. Pareto based EMO ranks the population of an evolutionary algorithm based on Pareto optimality. Its representative algorithms include SPEA II by Zitzler and Thiele (1999), non-dominated sorting genetic algorithm (NSGA) II by Deb et al. (2002), etc. Since Pareto based EMO does not work well for multiple objectives (e.g. four or more objectives), researchers have started to show interest in the other two families: indicator-based EMO that is guided by an indicator to measure the performance of the set and decomposition based EMO that divides the problem into several subproblems, each of which targets different parts of the Pareto front. The indicator-based evolutionary algorithm (IBEA) (Zitzler \& Künzli, 2004) and $S$ metric selection evolutionary multiobjective algorithm (SMS-EMOA) (Emmerich et al., 2005) fall into the category of indicator-based EMO. On the other hand, NSGA III (Deb \& Jain, 2014) belongs to the category of decomposition based EMO.

Early EMO approaches do not use an elite-preservation mechanism until the appearance of the second generation of EMO algorithms, such as NSGA II by Deb et al. (2002). Despite that, the second generation of EMO methods does not work well for multiple objectives (e.g. four or more objectives). As a result, the third generation of EMO methods, such as NSGA III by Deb and Jain (2014), is introduced to handle various decision making problems that involve more than four objectives. In recent years, some new EMO methods have been developed, which include particle swarm optimization (PSO), ant colony optimization algorithm (ACO), particle bee algorithm (PBA) and their variants.

\subsubsection{Methods with progressive information}

Methods with progressive information, also known as interactive methods, are generally used to obtain a most satisfactory solution through an iterative process that solves local problems, progressively involving the local preference of decision makers and providing current solutions. Reference point method is a common example of MODM methods in this category, which was proposed by Wierzbicki (1982) based on the achievement scalarizing function. The core idea of this method is directing the search by reference points that represent desirable values for objective functions and generating new alternatives by shifting reference points. The successor methods, such as satisficing trade-off method (STOM) (Nakayama, 1995) and given-unknown-equation-substitute-solve (GUESS) (Buchanan, 1997), share the same idea. Unlike the reference point method by Wierzbicki (1982) that uses reference points, the reference direction approach by Korhonen and Laakso $(1984,1985,1986)$ chooses a reference direction, which makes the search process more visual. Based on the nondifferentiable interactive multi-objective bundle-based optimization system (NIMBUS) method by Miettinen (1998), Miettinen and Mäkelä (2006) and Purshouse et al. (2014) developed the synchronous NIMBUS algorithm and the interactive EMO method respectively, which have gained comprehensive attention. By comparison, interactive methods are advantageous over non-interactive methods, such as no-preference methods, methods with a priori information and methods with a posteriori information. This is because decision makers usually have enough knowledge about problems but do not necessarily have a deep understanding of theories. 


\section{Methodology}

\subsection{Survey methodology}

Literature review plays a significant role in conveying the subject knowledge that has been established to readers. It has been improved considerably from traditional narrative review to SLR recently. Unlike traditional narrative review, SLR adopts a rigorous, replicable and transparent review process and meanwhile makes the decisions, procedures and conclusions of reviewers unbiased and traceable (Tranfield et al., 2003; Thomé et al., 2016). For this reason, an enormous application of SLR has been witnessed in different disciplines. The procedure of SLR can be commonly divided into: (1) formulating the question; (2) determining the required characteristics of primary studies; (3) retrieving the sample of potentially relevant literature; (4) selecting the pertinent literature; (5) synthesizing the literature; and (6) reporting the results (Durach et al., 2017).

As mentioned in the Introduction section, there are several existing attempts to review the literature on MCDM methods in construction, such as Jato-Espino et al. (2014) and Sierra et al. (2018). However, few of them are conducted in a systematic manner. Unlike existing literature reviews, this research uses a stepwise method for SLR to assess and aggregate previous research works. It further provides a balanced and objective summary of research evidence for the application of MCDM methods in construction. The detailed steps of searching and filtering can be found in Figure 3. To avoid any bias and random error, this research introduces reliability analysis. During exclusion, coding and classification, nonparametric test is performed to test the reliability of relevant inter-processes.

\subsection{Searching methodology}

This research mainly focuses on the application of MCDM in construction. Four research questions (see Figure 3) are answered through SLR. Based on the review of the literature on MCDM methods in general (see Section 1), the tendency of MCDM evolution is recognized. Subsequently, 59 keywords, including the mainstream methods mentioned in Sections 1.3 and 1.4, are identified in this research. The strings "decision making" and "construction" are first chosen to narrow the search scope to decision making in construction. Boolean logic "OR" is then used to combine the following string of keywords: "(TS=((decision making OR DM) AND construction AND (MCDM OR MCDA OR MADM OR MODM OR MRDM OR ACO OR AHP OR ANP OR ARAS OR BWM OR Choquet Integral OR COPRAS OR DASA OR DEA OR DEMATEL OR De Novo OR EDAS OR ELECTRE OR EMO OR FARE OR Fuzzy Set (theory) OR GA OR Grey Set OR Grey theory OR GUESS OR IBEA OR IDOCRIW OR IMP OR KEMIRA OR MABAC OR MAUT OR MOORA OR MULTIMOORA OR Multiple criteria OR Nondominated solutions generation method OR Normal boundary intersection methods OR Normal constraint method OR NSGA OR
NIMUS OR PBA OR PROMETHEE OR PSO OR Reference Point Method OR Rough Set OR Rough theory OR SAW OR SMS-EMOA OR SPEA OR SIR OR STOM OR Sugeno Integral OR SWARA OR TOPSIS OR VIKOR OR WASPAS OR Weighting method OR Goal programming)))".

\subsection{Selection of data sources and papers}

Core collection in Web of Science, a comprehensive scientific citation indexing service provider, is selected as the database for the literature search. Only the articles written in English and citied by Science Citation Index Expanded (SCIE) or Social Science Citation Index (SSCI) are retrieved as the potential literature. The literature search shows very few related articles published before 2000. Therefore, a timespan from 2000 to 2019 was chosen and the baseline sample including 1658 articles in 596 journals was found during the literature search on $30^{\text {th }}$ March 2020. Three exclusion filters are adopted for the baseline sample in order to generate the final literature sample. The first filter excludes the journals that contain less than two articles. As a result, it becomes more possible to ensure the homogeneity of selected articles. The second and third filters eliminate the articles that fall outside the scope of this research through reading titles/abstracts and full contents, respectively.

To ensure the accuracy of literature screening, the whole process is conducted by the first and second authors separately. The individual results of each screening are tested by the related samples McNemar test, a nonparametric test that examines if the statistically significant change exists on a dichotomous trait at two time points for dependent samples. According to the test results, all three pairs pass the test (see Table 1). In other words, no possible bias or error is detected in terms of literature screening. For any different opinions between each filter, joint decision is made after discussion between the first and second authors. Finally, 530 articles from 125 journals are selected as the final literature sample.

\subsection{Thematic classification}

Content co-occurrence analysis is a systematic and objective means to extract the themes of science and detect the linkages between these themes directly from the subject contents of texts (Sedighi, 2016). Since abstracts are considered as concise descriptions of research contents, this research constructs the distance-based map of terms in titles and abstracts based on content co-occurrence analysis to identify the themes of MCDM application in construction. VOSviewer, a bibliometric mapping software package, is adopted to create the map. A total of 88 terms that occur more than three times are selected from 11841 terms after excluding the term "MCDM methods" and general terms, such as "system" or "method". Figure 4 shows the results of content co-occurrence analysis, in which nodes represent terms while the distance between two nodes reflects the strength of their linkage. Colors indicate the clusters to which terms are assigned through similarity analysis (van Eck \& Waltman, 2010). 


\begin{tabular}{|c|c|c|c|}
\hline Step & Procedure & & Content \\
\hline $\begin{array}{l}\text { Step } 1 \\
\text { Fumulate } \\
\text { research } \\
\text { question }\end{array}$ & $\begin{array}{c}\downarrow \\
\text { Fumulate } \\
\text { research question }\end{array}$ & & $\begin{array}{l}\text { RQ1: What is the bibliometric perspective of MCDM in the Construction field? } \\
\text { RQ2: In which research areas and field applications are MCDM methods applied } \\
\text { in Construction? } \\
\text { RQ3: What are the challenges potentially related? } \\
\text { RQ4: What are the research tendencies? }\end{array}$ \\
\hline $\begin{array}{l}\text { Step 2 } \\
\text { Determine } \\
\text { required } \\
\text { characteris- } \\
\text { tics of } \\
\text { primary } \\
\text { studies }\end{array}$ & \begin{tabular}{|c|}
\multicolumn{1}{c}{$\begin{array}{c}\text { Fumulate } \\
\text { Keyword }\end{array}$} \\
$\downarrow$ \\
$\begin{array}{c}\text { Craft } \\
\text { inclusion \& } \\
\text { exclusion criteria }\end{array}$
\end{tabular} & & $\begin{array}{l}\text { Inclusion Criteria: } \\
\text { - Timespan: 2000-2019 } \\
\text { - Language: English } \\
\text { - Document Types: Peer-reviewed journal article } \\
\text { - Index: SCI Expanded, SSCI } \\
\text { Exclusion } \\
\text { Criteria: } \\
\text { - The journal including less than } 2 \text { articles } \\
\text { - The article outside the research scope after reading the title \& abstract } \\
\text { - The article outside the research scope after reading the full contents }\end{array}$ \\
\hline $\begin{array}{c}\text { Step } 3 \\
\text { Retrieve } \\
\text { sample of } \\
\text { potentially } \\
\text { relevant } \\
\text { literature } \\
\end{array}$ & \begin{tabular}{|c|} 
Database \\
$\mathrm{N}=1658, \mathrm{~J}=596$
\end{tabular} & & $\begin{array}{l}\text { Database: Web of Science } \\
\text { Searching the keyword } \\
\text { Deriving the baseline sample: } \mathrm{N}=1658, \mathrm{~J}=596\end{array}$ \\
\hline $\begin{array}{l}\text { Step } 4 \\
\text { Select } \\
\text { pertinent } \\
\text { literature }\end{array}$ & $\begin{array}{c}\text { Database } \\
\mathrm{N}=530, \mathrm{~J}=125\end{array}$ & No & $\begin{array}{l}\text { Reducing the baseline sample to derive the synthesis sample: } \\
\text { Exclusion(EXCL) Criteria 1: Remove the journal including solely } 1 \text { article; } \\
\text { Exclusion(EXCL) Criteria 2: Remove the articles that outside the scope of research } \\
\text { after reading the title and abstract } \\
\text { Exclusion(EXCL) Criteria 3: Remove the articles that reading the full articles } \\
\text { Non-parameter Test: } \\
\text { Related Samples McNemar test: the null hypothesis is the distributions of different } \\
\text { values across two results are equally likely, if the significance is more than the } \\
\text { significance level } 0.05 \text {, then the decision is retain the null hypothesis. }\end{array}$ \\
\hline $\begin{array}{l}\text { Step } 5 \\
\text { Synthesize } \\
\text { literature }\end{array}$ & $\begin{array}{c}\text { Apply coding } \\
\text { schemes to extrat } \\
\text { information }\end{array}$ & No & $\begin{array}{l}\text { Coding the synthesis sample } \\
\text { Summarizing the findings (methodological aspects of the primary study should be } \\
\text { analyzed) and interpretation } \\
\text { Non-parameter Test: } \\
\text { Wilcoxon signed ranks test: the null hypothesis is the median of differences } \\
\text { between two time points equals } 0 \text {, if the significance is more that the significance } \\
\text { level } 0.05 \text {, then the decision is retain the null hypothesis. }\end{array}$ \\
\hline $\begin{array}{l}\text { Step } 6 \\
\text { Report the } \\
\text { results }\end{array}$ & $\begin{array}{l}\text { Result and } \\
\text { updating the } \\
\text { review }\end{array}$ & & $\begin{array}{l}\text { Descriptive analysis of primary studies } \\
\text { Outlining the knowledge derived from the study synthesis } \\
\text { Keeping the review updated }\end{array}$ \\
\hline
\end{tabular}

Figure 3. Steps of literature searching and filtering 
Table 1. Nonparametric test for filtering

\begin{tabular}{|c|c|c|c|c|c|}
\hline No. & Content & Frequency for agree & Frequency for disagree & Nonparametric test & Sig. \\
\hline 1 & The result of the $1^{\text {st }}$ filter & 1274 & 0 & Related samples McNemar test & 1.000 \\
\hline 2 & The result of the $2^{\text {nd }}$ filter & 551 & 3 & Related samples McNemar test & 1.000 \\
\hline 3 & The result of the $3^{\text {rd }}$ filter & 530 & 2 & Related samples McNemar test & 1.000 \\
\hline
\end{tabular}

Note: The significant level is 0.05 .

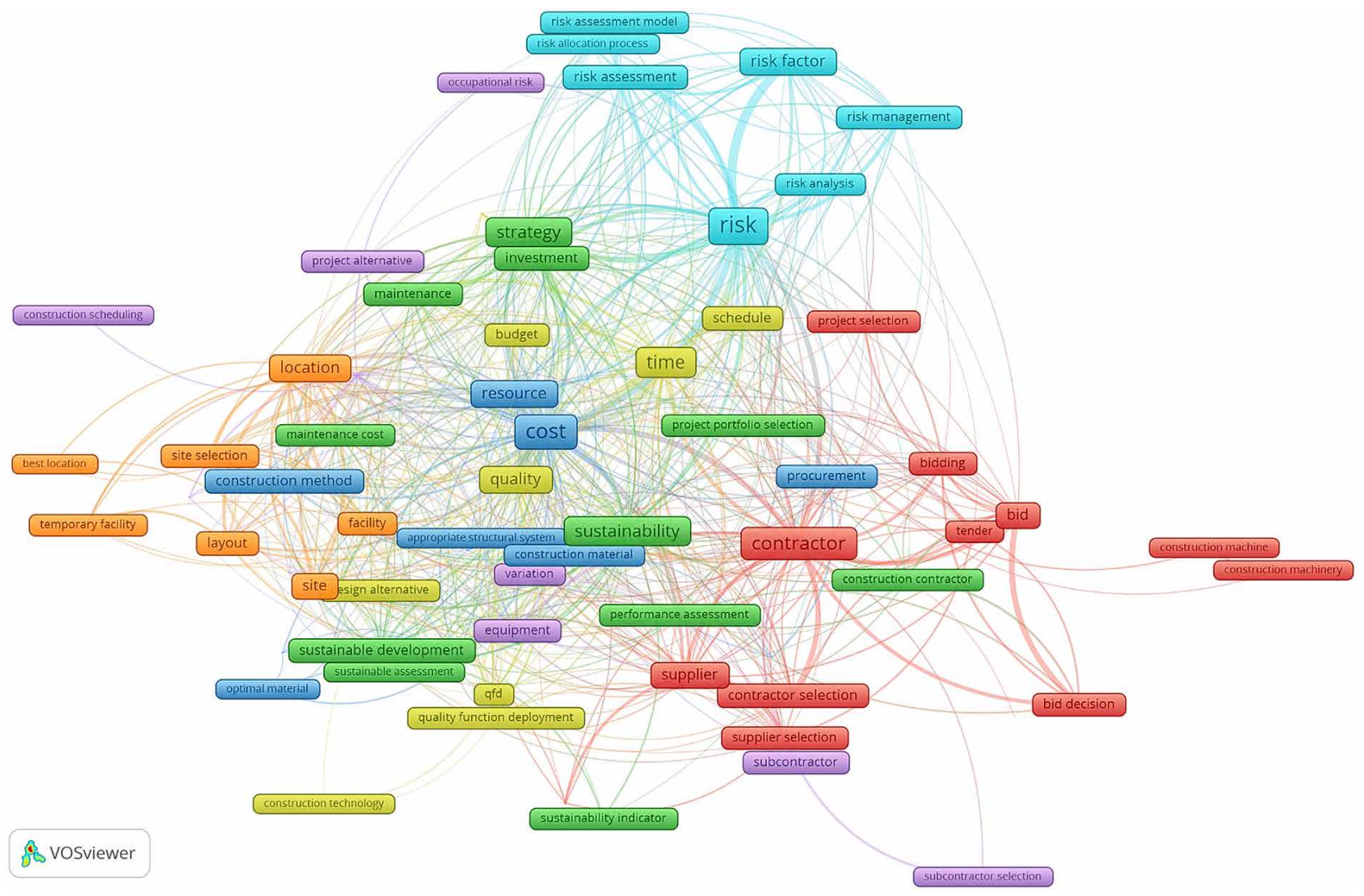

Figure 4. Content co-occurrence analysis of terms in titles and abstracts

As shown in Figure 4, seven major themes for MCDM application in construction are identified, including: (1) contractor (subcontractor) / staff / supplier selection (in red); (2) cost / time / quality performance assessment (in yellow); (3) design /system / method / project / portfolio selection (in blue); (4) layout / location selection (in orange); (5) material/ equipment selection (in purple); (6) risk / safety management (in light blue); and (7) sustainability / environment assessment (in green). According to Cobo et al. (2011), sometimes it is hard to determine to which cluster borderline terms belong when using software packages, such as VOSviewer, for bibliometric analysis. In these cases, adjustment by researchers is necessary, taking research questions into consideration. Such adjustment is also included in this research when classifying MCDM application in construction into seven major themes according to the meaning of each term and the essence of each theme.

In order to ensure the objective adjustment and accurate classification, the similar procedure with screening process is conducted to classify the 530 articles into the appropriate themes and subthemes. Obviously, there are continuous observations rather than dichotomies for the themes and subthemes. Therefore, Wilcoxon signed ranks test, a non-parametric test that measures two occasions and assesses the statistically significant differences between two time points, is employed to verify the consistency of the classification results. For the coding theme (frequency for disagree is 18) and subthemes (frequency for disagree is 12), both significances (0.017 and 0.013, respectively) are smaller than 0.05 , which reflect that the first and second authors did not elicit a statistically significant difference in the classification results.

\section{Bibliometric analysis of MCDM methods in construction}

\subsection{Distribution by publication years}

The distribution of 530 articles on MCDM methods in construction by publication years is presented in Figure 5. Despite particular fluctuations, on the whole the number of relevant publications increased from one in 2002 to 140 
in 2019. Different research trends are found for MADM and MODM methods. Since 2005, the number of research papers on MADM methods is usually greater than those on MODM methods, especially in recent years (see Figure 5). Compared to MADM, MODM requires a larger amount of data to achieve a desired level of performance. For this reason, MODM is less utilized and therefore MADM dominates in construction. The number of papers on MADM gradually increased from the minimum in 2005 to the maximum in 2019 although there were slight falls in 2013, 2015 and 2016. On the other hand, the number of papers on MODM methods fluctuated from 2005 to 2019, during which the peak appeared in 2019.

As seen in Figure 6, the number of papers on single methods was greater than the number of hybrid methods from 2005 to 2007. The trend reversed since 2008. As a result, hybrid methods were more commonly observed than single methods from 2008 to 2019. The gap between the two categories increased dramatically in recent four years. Figure 6 shows that the application of hybrid methods in construction rose steadily from 2005 to 2019 with an exception in 2013. On the other hand, the application of single methods fluctuated during the same period with a peak in 2019. As mentioned above, decision making in construction projects is becoming complicated and difficult due to the sophistication of technologies and the increase in complexity and dynamics. The combination of different MCDM methods offsets one's demerits by another's merits and therefore better addresses the decision making problem. This explains why hybrid methods become more popular in construction.

Based on the trend analysis, the application of soft computing methods and crisp set methods in construction is presented in Figure 7. It can be seen that both categories have experienced a similar trend regardless of a slight difference. Both of them increased slowly in the initial years from 2000 to 2013 and attracted a significant increase in the last five years. By comparison, the application of crisp set methods is slightly more than that of soft computing methods during the recent 15 years except for 2011-2013 and 2016. With regard to the soft computing methods, the overwhelming majority of publications adopt fuzzy set related methods in comparison with rough set and grey set related methods. This phenomenon can be corroborated from the literature review in Section 1.3, which is due to the continuous development of fuzzy set methods and the popularization of its joint use with other MCDM methods.

\subsection{Distribution by journals}

After the screening process, 125 journals are left in this research for the literature review. Table 2 presents a list of 21 selected journals that contain at least five papers. Among these journals, Journal of Civil Engineering and Management ranks first, contributing $8.30 \%$ of selected articles. It is followed by Journal of Construction Engineering and

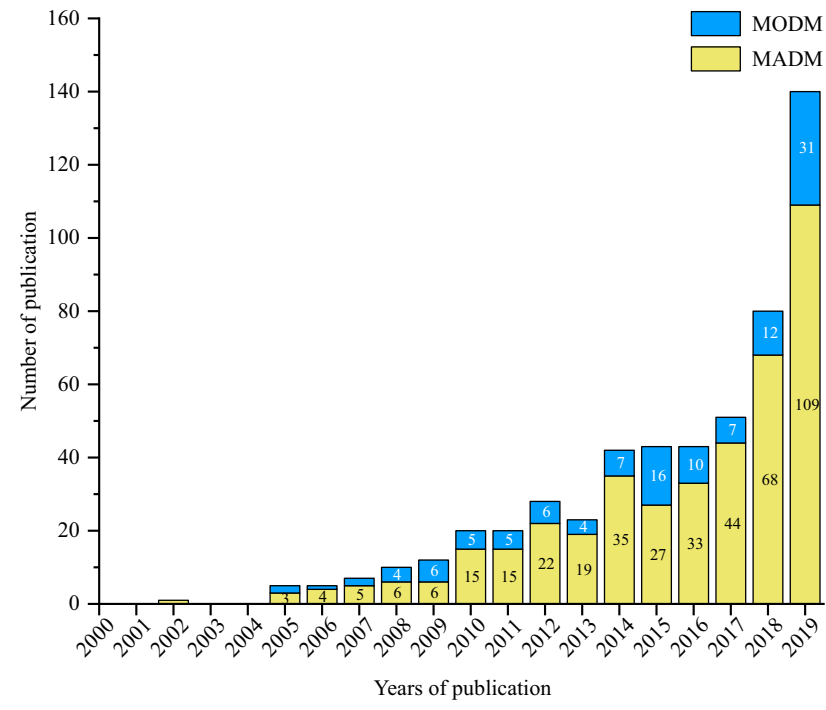

Figure 5. Distribution of publications on MADM and MODM methods

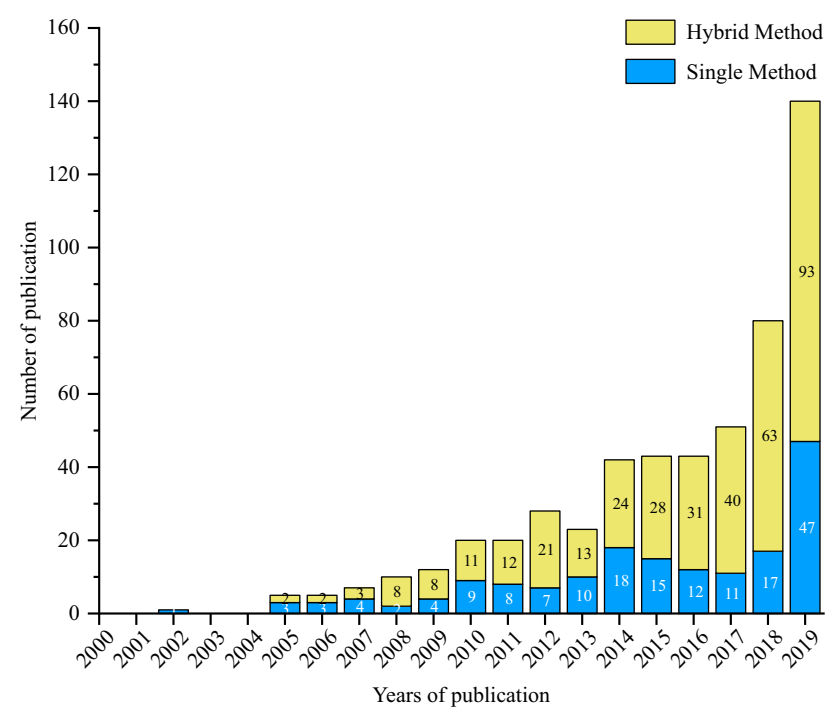

Figure 6. Distribution of publications on single and hybrid methods

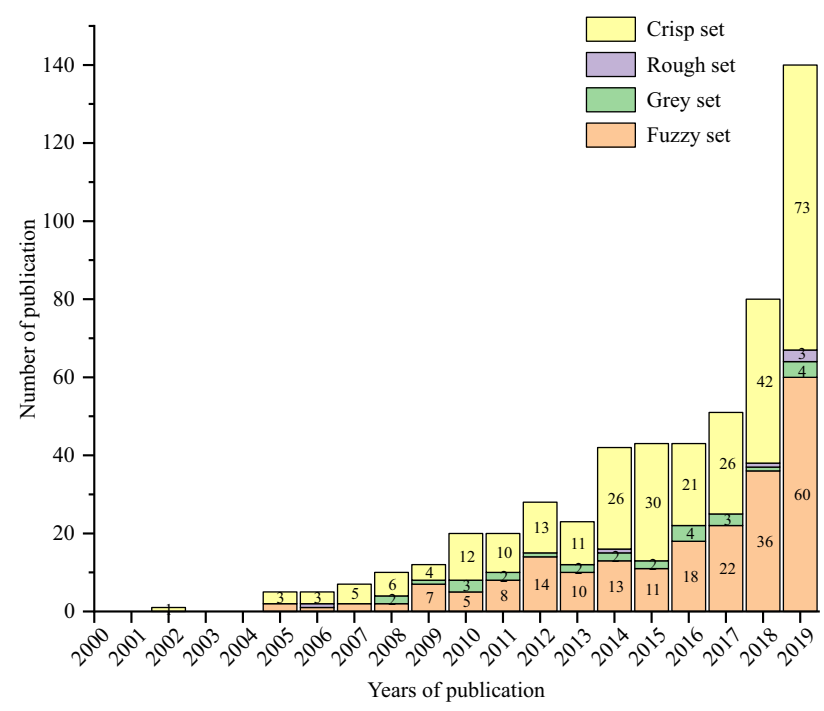

Figure 7. Distribution of publications on soft computing methods and crisp set methods 
Management (7.74\%), Automation in Construction (5.85\%), Sustainability (5.47\%) and Journal of Management in Engineering (3.40\%). Most selected articles are published in construction, engineering or construction/engineering management journals. Some articles are published in sustainability and environment related journals.

\subsection{Distribution by authors}

Table 3 shows the top eight authors, each of whom has at least five articles on MCDM methods in construction. The number of their articles and the number of their articles' citations are also presented in Table 3. By comparison, Professor Edmundas Kazimieras Zavadskas from Vilnius Gediminas Technical University is the most authoritative author who has 40 articles on MCDM methods in construction. By the end of March 2020, these articles have been cited for 1547 times.

\subsection{Distribution by MCDM methods}

As mentioned above, a total of 530 papers are selected for the literature review, based on which it is possible to identify 29 single methods and 94 hybrid methods. The top five most commonly used signal methods are: AHP (60 papers; $11.32 \%$ ), fuzzy theory (52 papers; $9.81 \%$ ), GA (24 papers; $4.53 \%)$, DEA (16 papers; $3.02 \%$ ), and ANP (14 papers; $2.64 \%$ ). Among the hybrid methods used in construction, fuzzy-AHP method (53 papers; $10.00 \%$ ) ranks first, which is followed by fuzzy-TOPSIS (28 papers; $5.28 \%$ ), AHP-fuzzy-TOPSIS (8 papers; $1.51 \%$ ), fuzzy-ANP (8 papers; $1.51 \%$ ), ANP-DEMATEL (7 papers; $1.32 \%$ ), and fuzzy-DEMATEL (7 papers; $1.32 \%$ ). By comparison, hybrid methods that contain fuzzy logic (159 papers; $30.00 \%$ ) and hybrid methods that contain AHP (104 papers; $19.62 \%$ ) can be considered as the largest two hybrid groups.

Table 2. Distribution of journals

\begin{tabular}{|c|c|c|c|c|}
\hline No & Journal title & Frequency & Percentage & Cumulative percentage \\
\hline 1 & Journal of Civil Engineering and Management & 44 & $8.30 \%$ & $8.30 \%$ \\
\hline 2 & Journal of Construction Engineering and Management & 41 & $7.74 \%$ & $16.04 \%$ \\
\hline 3 & Automation in Construction & 31 & $5.85 \%$ & $21.89 \%$ \\
\hline 4 & Sustainability & 29 & $5.47 \%$ & $27.36 \%$ \\
\hline 5 & Journal of Management in Engineering & 18 & $3.40 \%$ & $30.75 \%$ \\
\hline 6 & Expert Systems with Applications & 16 & $3.02 \%$ & $33.77 \%$ \\
\hline 7 & Journal of Cleaner Production & 15 & $2.83 \%$ & $36.60 \%$ \\
\hline 8 & Mathematical Problems in Engineering & 11 & $2.08 \%$ & $38.68 \%$ \\
\hline 9 & Archives of Civil and Mechanical Engineering & 10 & $1.89 \%$ & $40.57 \%$ \\
\hline 10 & Journal of Intelligent and Fuzzy Systems & 10 & $1.89 \%$ & $42.45 \%$ \\
\hline 11 & KSCE Journal of Civil Engineering & 10 & $1.89 \%$ & $44.34 \%$ \\
\hline 12 & Building and Environment & 8 & $1.51 \%$ & $45.85 \%$ \\
\hline 13 & Energy and Buildings & 8 & $1.51 \%$ & $47.36 \%$ \\
\hline 14 & Engineering, Construction and Architectural Management & 8 & $1.51 \%$ & $48.87 \%$ \\
\hline 15 & International Journal of Project Management & 8 & $1.51 \%$ & $50.38 \%$ \\
\hline 16 & International Journal of Strategic Property Management & 8 & $1.51 \%$ & $51.89 \%$ \\
\hline 17 & Symmetry-Basel & 8 & $1.51 \%$ & $53.40 \%$ \\
\hline 18 & Journal of Computing in Civil Engineering & 7 & $1.32 \%$ & $54.72 \%$ \\
\hline 19 & Safety Science & 7 & $1.32 \%$ & $56.04 \%$ \\
\hline 20 & Sustainable Cities and Society & 7 & $1.32 \%$ & $57.36 \%$ \\
\hline 21 & Technological and Economic Development of Economy & 7 & $1.32 \%$ & $58.68 \%$ \\
\hline 22 & Others & - & $41.32 \%$ & $100.00 \%$ \\
\hline
\end{tabular}

Table 3. Publications on MCDM in construction by authors

\begin{tabular}{|c|l|c|c|c|l|c|c|}
\hline No & \multicolumn{1}{|c|}{ Author } & $\begin{array}{c}\text { No. of } \\
\text { articles }\end{array}$ & $\begin{array}{c}\text { No. of } \\
\text { citations }\end{array}$ & No & \multicolumn{1}{|c|}{ Author } & $\begin{array}{c}\text { No. of } \\
\text { articles }\end{array}$ & $\begin{array}{c}\text { No. of } \\
\text { citations }\end{array}$ \\
\hline 1 & Edmundas Kazimieras Zavadskas & 40 & 1547 & 5 & Guiwu Wei & 8 & 89 \\
\hline 2 & Zenonas Turskis & 25 & 1107 & 6 & Yi-Kai Juan & 6 & 165 \\
\hline 3 & Jolanta Tamošaitiene & 12 & 657 & 7 & Abdolreza Yazdani-Chamzini & 6 & 133 \\
\hline 4 & Jurgita Antucheviciene & 12 & 250 & 8 & Heng Li & 6 & 70 \\
\hline
\end{tabular}




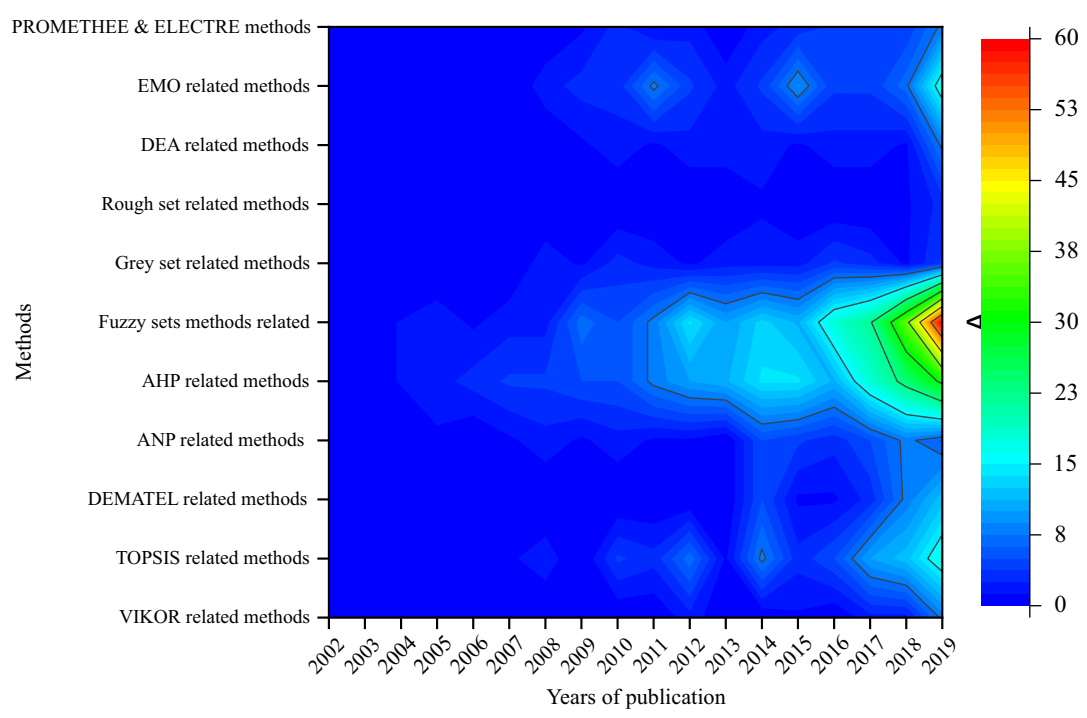

Figure 8. Counter map for single and hybrid methods by publication years

As seen in Figure 8, a contour map presents the distribution of single and hybrid methods by publication years. AHP-related methods cover both single AHP and hybrid methods that contain AHP. Similarly, fuzzy-related methods refer to both single fuzzy algorithm and hybrid methods that contain fuzzy algorithm. It is clearly shown in Figure 8 that research using AHP-related and fuzzyrelated methods has become more and more intensive in recent ten years. In Figure 8, EMO-related methods mean single and hybrid methods that have relevance to EMO. The contour map in Figure 8 shows slight concentration on research using EMO-related methods during 20102011, 2014-2015 and 2017-2019, respectively, although there is no continuous research evidence for the use of EMO-related methods. On the other hand, slight concentration on research on TOPSIS-related methods can be observed during 2011-2012, 2013-2014 and 2016-2019, respectively.

\section{Discussion about application themes}

\subsection{Contractor (subcontractor)/staff/supplier selection $($ article number $=74)$}

\subsubsection{Bidding}

For the potential participants of a project, whether to bid or not bid for the project is one of the most crucial decisions. During the bidding process, a bidder has to find a balance between the expected profit and the chance of winning (Chou et al., 2013). For this purpose, there are generally three solving ideas. The first idea is pair-wising the factors that influence the bid decision to generate their weights and then calculating the bid numbers or comparing the bid alternatives. AHP and improved AHP methods are widely used for this purpose. Fuzzy set (Chou et al., 2013; Plebankiewicz, 2014) and rough set (Shi et al., 2016) can be incorporated into AHP to reflect the human way of thinking and perform the evaluation of linguistic vari- ables. Another idea is developing a benchmark based on expert knowledge and historical information and subsequently providing a ranking of different projects to bid in reference to the benchmark for bid project selection. Fuzzy-TOPSIS (Al-Humaidi, 2016) and DEA methods (El-Mashaleh, 2013; Polat \& Bingol, 2017) can be adopted under this circumstance. The last idea is estimating project award prices with the help of artificial intelligence (AI) models, such as artificial neural networks (ANN) and general regression neural network (GRNN) (Shi et al., 2016).

\subsubsection{Contractor/subcontractor/supplier selection}

Appropriate contractor (subcontractor) and supplier selection is a key to the success of a project (Nieto-Morote \& Ruz-Vila, 2012; Abbasianjahromi et al., 2013; Seth et al., 2018). In construction practice, such selection is usually divided into prequalification and bid evaluation (Hasnain et al., 2018). In theory, the client of a project has to select the most competent contractor based on its capability in various aspects. It is the same for the contractor of a project to select its subcontractors and suppliers. How to identify and weight the criteria for measuring the capability of the contractor, subcontractors or suppliers is crucial for right selection. Most MCDM methods can be used to solve this problem. In recent years, some new MCDM methods have been applied to improve the solution. For the identification of selection criteria, single membership is the weakness of traditional fuzzy set methods. Intuitionistic fuzzy values replace single membership values to measure the hesitation margin of decision makers, which make the measurement of uncertainty and fuzziness more flexible (Palha et al., 2016; Wan et al., 2016). Compared to the traditional AHP and/or fuzzy set methods, determining the weights for selection criteria by the hybrid method, such as the combination of DEMATEL, BWM and grey set methods (Yazdani et al., 2019) and the combination of EMO methods (e.g. GA) and fuzzy set methods (Lin et al., 2008), would make the selection model more consistent. 


\subsubsection{Partner/staff selection}

Since project participants play a significant role in project performance, the selection of staff and partners in a project has received considerable academic attention in recent years. Relevant studies can be divided into decision making hierarchy and selection methodology (Shahhosseini \& Sebt, 2011). The research on staff selection targets project managers (Zavadskas et al., 2012b; Afshari, 2015, 2017) and key personnel (Shahhosseini \& Sebt, 2011). The selection of staff is mainly based their capability and suitability for the work. On the other hand, the research on partner selection solves the problem from broader aspects, such as the ranking of alternatives (Radziszewska-Zielina, 2010) and the trade-off between minimizing the negative environmental impact and maximizing the positive business performance (Wu \& Barnes, 2016). In terms of staff/partner selection, there are relatively more subjective criteria represented by linguistics and vague patterns. Therefore, fuzzy set theory and its related hybrid methods are more efficient under such a circumstance (Shahhosseini \& Sebt, 2011). This explains why fuzzy-Delphi method (Afshari, 2015) and fuzzy-AHP (Chen \& Wu, 2012) are chosen for the selection of project managers and partners respectively. Despite that, fuzzy-Delphi and fuzzy-AHP are still considered as traditional fuzzy set methods, which cannot extract fuzzy rules from the history data. As a result, adaptive neuro-fuzzy inference system (ANFIS) is applied to increase the adaptive ability of a selection model (Shahhosseini \& Sebt, 2011).

\subsection{Cost/time/quality performance assessment $($ article number $=91)$}

\subsubsection{Time, cost or quality performance assessment}

Performance assessment is often described as a systematic way of measuring project performance by evaluating the inputs, activities and outputs regarding each project objective (e.g. cost, time and quality). A majority of researchers have tried to build frameworks that allow decision makers to better understand the situation of performance assessment without being overwhelmed by its complexity. Both quantitative and qualitative variables are involved when establishing frameworks to comprehensively reflect the assessment. Fuzzy logic (Gunduz et al., 2015) and its variants, such as fuzzy-ANP (Kabak et al., 2014) as well as fuzzyAHP and fuzzy-TOPSIS (Liang et al., 2017a), are widely used to deal with the uncertain and imprecise information during the assessment. Due to the complexity of performance assessment, it is difficult to define a specific functional equation. Without assuming a particular functional form, DEA (Tsolas, 2013) and its related hybrid methods, such as DEA-principal component analysis (PCA) (Iyer \& Banerjee, 2016), and fuzzy-related hybrid methods, such as fuzzy-AHP and fuzzy-DEA (A. S. Loron \& M. S. Loron, 2015), are also popularly used for identifying the benchmarks to compare the alternatives. To further imitate the decision making process in the human brain, evolutionary fuzzy neural inference model (EFNIM), which combines
GA, fuzzy logic and neural network, exerts the advantages and avoids the drawbacks of each single method. Such a combined method can be used to solve the complex decision making problems, such as budget allocation performance (Cheng et al., 2008) and construction productivity forecast (Mirahadi \& Zayed, 2016).

\subsubsection{Trade-off}

In construction projects, trade-off can be divided into time-cost-resource utilization optimization (TCRO) (Zahraie \& Tavakolan, 2009), time-cost-quality trade-off (Diao et al., 2011), and time-cost-environment impact (TCEI) (Ozcan-Deniz et al., 2012). TCRO can be further divided into the resource-constrained project scheduling problem (RCPSP) that minimizes the time of project completion under resource restrictions and the resource leveling problem (RLP) that allocates resources under project completion time constraints (Li et al., 2018). The exact (i.e. enumerative, dynamic programming, linear programming, etc.), heuristics (i.e. inductive method, local search method, etc.), and metaheuristics methods (i.e. EMO, etc.) are often employed to solve the problems mentioned above (Eshtehardian et al., 2009). Compared to exact methods and heuristics, metaheuristics methods can more thoroughly explore the solution space and therefore are more flexible for the problems mentioned above. It is found in this research that two articles adopt heuristics methods while 13 articles utilize metaheuristics methods among a total of 15 articles on the trade-off problems. As the second generation of EMO algorithms, NSGA-II (Monghasemi et al., 2015) is the most popular metaheuristics method for the trade-off problems.

\subsection{Design/system/method/project/portfolio selection $($ article number $=109$ )}

\subsubsection{Design selection}

There is a growing body of literature that recognizes the importance of decision making during the design process (Tiwari et al., 2017). Since the design proposed by architects and designers is sometimes not conducive to construction contractors or not satisfied by customers and end-users, user-centered design has drawn an increasing attention recently. Compared to MADM methods, MODM methods provide more choices to customers for selection. For this reason, MODM methods, such as DEA (Cariaga et al., 2007) and case-based reasoning (CBR)-GA (Cebi et al., 2010), are mostly used to deal with user-centered design. Another important issue is the comparison of different design schemes according to predetermined criteria. Curiel-Esparza and Canto-Perello (2013) used AHP to select utility tunnels techniques. Reizgevicius et al. (2014) adopted hybrid TOPSIS multifunctional methods to evaluate $4 \mathrm{D}$ computer-aided design. In construction today, building information modeling (BIM) is widely recognized as a digital revolution. With the emergence of BIM, however, the number of possible design solutions increase markedly, which may cause impracticability for 
determining the optimal solution (Inyim et al., 2015). In this case, stochastic optimization methods (e.g. NSGA-II) is often chosen to solve the complex design problem (Migilinskas et al., 2017), such as rock-fill dam design (Nikoo et al., 2015) and sewerage rehabilitation design (Lin et al., 2016).

\subsubsection{Management system/construction method selection}

Project management systems and construction methods play a vital role in project delivery and success. Instead of rigorous data, the selection of project management systems and construction methods is largely based on acquaintance and preference (Chen et al., 2010). MCDM and its integrated methods, which measure both tangible and intangible variables in intricate and varied circumstances, can handle the selection of project management systems and construction methods effectively and efficiently (Chen, 2018). Taking project delivery system (PDS) selection as an example, DEA and ANN (Chen et al., 2011), RST (Liu et al., 2015a, 2016a), fuzzy multi-criteria group decision making (FMCGDM) (Khanzadi et al., 2016), and interval-valued intuitionistic fuzzy set (IVIFS) (An et al., 2018) can be observed within the relevant literature. Although various studies have been conducted to explore the mechanism for the selection of appropriate tools, a common trend is the integration of MCDM methods and simulation technologies, which avoids the reliance on costly experimental tests or historical data. For instance, Khoramshokooh et al. (2018) explored cut-off wall selection with the combination of PROMETHEE and multilayer perceptron (MLP) simulation model while Marzouk and Al Daour (2018) investigated labor evacuation of construction sites through the mass motion simulation platform based on TOPSIS.

\subsubsection{Project/portfolio selection}

Where the selection of a construction project is concerned, the client of the project should consider both financial and nonfinancial criteria when choosing the best project alternative (Dikmen et al., 2007). Establishing an objective evaluation model that can thoroughly evaluate the feasibility of each project alternative and determine its prioritization is paramount important. During the process of project selection, the traditional analysis fails to analyze qualitative attributes that cannot be easily expressed in monetary terms (Yan et al., 2011). To eliminate this limitation and meanwhile realistically and accurately measure the preference of decision makers, different intuitionistic fuzzy techniques are often used for project selection, such as intuitionistic fuzzy Einstein correlated averaging (IVIFECA), intuitionistic fuzzy TOPSIS (IFT) and dynamic intuitionistic fuzzy weighted averaging (DIFWA) (Gu et al., 2014; Ghoddousi et al., 2018). Since single project selection does not consider the interaction between projects (Ghapanchi et al., 2012), the selection of project portfolio has increasingly drawn research attention in recent years.
For example, Abbasianjahromi and Rajaie (2012) selected a portfolio based on the risk endurable level while Ghapanchi et al. (2012) investigated the efficiency of project portfolio. The MCDM methods used for single project selection also apply to project portfolio selection.

\subsection{Layout/location selection $($ article number $=56$ )}

\subsubsection{Network design/location selection}

Network design refers to the decision making problem that determines the optimal planning, maintains the transport networks for different purposes, and reduces the negative impacts on environment (Zolfani et al., 2011; Miandoabchi et al., 2015). There are two types of relevant solutions for transport networks (i.e. alternatives). One is based on the use of MADM methods. For example, hybrid AHP (Zolfani et al., 2011) and fuzzy-TOPSIS (Liang et al., 2017b) are proposed to select from a limited number of predetermined alternatives. The other is based on the use of MODM methods. For example, GA and multi-objective B-cell algorithm (Miandoabchi et al., 2015) are adopted to obtain a set of Pareto-optimal solutions.

Project location is always restrained by a set of constraints and can be generally selected by three types of MCDM methods. The first is single or hybrid MADM methods, such as ELECTRE II (Dosal et al., 2012) and fuzzy-AHP (Ardeshir et al., 2014a). The second is combined with spatial analysis techniques, such as geographic information systems (GIS) (Gumusay et al., 2016) and spatial database management system (SDBMS) (DíazCuevas et al., 2018). The third is transforming the decision making problem, especially material source selection, into the classic transhipment problem, which can be solved by MODM methods, such as binary linear programming models (Jaskowski et al., 2014).

\subsubsection{Site layout planning}

Construction site layout planning and facility layout design are essential decision making processes during which available site facilities are allocated to free locations to deliver construction projects in a safer, more efficient and effective manner (Cheng \& Lien, 2012; Ning et al., 2016). However, site layout planning and design represent a complicated task due to the conflicting objectives, diversity of decision criteria, and variety of possible solutions associated with construction projects (RazaviAlavi \& AbouRizk, 2017). Compared to MADM methods, it is appropriate to utilize MODM methods to deal with site layout planning and design. The decision making framework can be generally divided into alternatives identification, layout optimization, evaluation and selection. During the process of alternatives identification, fuzzy logic is employed to address uncertain factors (Ning et al., 2011) or represent the closeness of facilities (Xu et al., 2016). The processes of optimization, evaluation and selection result in a set of elite site layout existed solutions that are both feasible (i.e., completely satisfy hard constraints) and qualified (i.e., sat- 
isfy soft constraints to the highest levels). Since examining all possible solutions is almost impossible, metaheuristic optimization methods, such as PBA (Cheng \& Lien, 2012), ACO (Adrian et al., 2015), multi-objective simulated annealing-based GA (MOSA-based GA) (Xu et al., 2016), and GA-based simulation optimization method (Lu et al., 2018) are taken to find the limited number of non-dominated solutions for further selection.

\subsection{Material/equipment selection $($ article number $=35)$}

The appropriate use of construction material and equipment is a prerequisite to the quality and efficient execution of construction activities in a project (Ćirović \& Plamenac, 2006; Rahman et al., 2012). Actually, the process of material and equipment selection is inherently a multifaceted cost and benefit trade-off, which is further compounded by the complexity and the unique context of the project (Shapira \& Goldenberg, 2005; Goldenberg \& Shapira, 2007). Some research attempts have been made for equipment selection, comparing equipment alternatives or estimating equipment parameters. The overwhelming majority is selecting the optimal equipment from a limited number of alternatives. For this reason, MADM methods are chosen predominantly for equipment selection. For example, fuzzy-TOPSIS method was adopted by Yazdani-Chamzini and Yakhchali (2012) for tunnel boring machine (TBM) selection while VIKOR, TOPSIS and PROMETHEE combined methods were employed by Masoumi et al. (2018) for monitoring instrument selection. Compared to MADM methods, article by Zhai et al. (2018) was the only within the reviewed publications using GA as a MODM method, which extracted load cycles of wheel loaders. Material selection is essentially the same as equipment selection, for which both MADM and MODM methods can be applied. Unlike equipment selection that mainly relies on MADM methods, MODM methods are more commonly adopted to determine the material ratio or combination for material selection. For example, AHP and multi-objective optimization models were recommended by Yepes et al. (2015) for the selection of reinforced concrete (RC) beams while AHP and fuzzy MOORA were introduced by Ilce and Ozkaya, (2018) for the selection of raised floor materials.

\subsection{Risk/safety management $($ article number $=82)$}

The dynamic nature of construction projects results in circumstances of high uncertainty and risk (Taylan et al., 2014). Risk management is a pivotal component of the decision making process and plays a significant role in project success (KarimiAzari et al., 2011). It can be divided into three processes, namely risk identification, risk assessment and risk mitigation (Salah \& Moselhi, 2016). During the three processes, MCDM methods are generally involved to achieve different purposes. As a particular area of risk management, safety management follows the general procedures of risk management and uses the
MCDM methods for safety issues. Risk identification helps decision makers in a construction project to identify risk factors associated with the project. For example, Li et al. (2013) proposed an improved AHP method to identify risk factors during open-cut subway construction. Chien et al. (2014) applied DEMATEL to pinpoint risk factors when implementing new technologies in construction projects.

Based on risk identification, risk assessment evaluates the potential adverse effect. Risk assessment approaches range from classical methods to fuzzy set techniques (KarimiAzari et al., 2011). The classical ones refer to the quantitative methods using the loss expectancy theory, which describes a risk source as a function of possibility (likelihood) and consequence of its occurrence (Samantra et al., 2017). On the other hand, MCDM methods are adopted to calculate the weight of each risk factor, which may include fault tree analysis (Ardeshir et al., 2014b), probabilistic cost estimation process model (Cha \& Lee, 2018), and Bayesian network model (Malekmohammadi \& Moghadam, 2018). The information of risk is often uncertain and inaccurate in construction practice. For this reason, fuzzy set techniques are utilized to measure both quantitative and qualitative factors, taking the uncertainty and inaccuracy of factors into consideration during risk assessment. The basic idea is assessing both the significance of risk (SR) and the influence of risk (IR), and then ranking different risk factors based on SR and IR. Fuzzy set theory (Zhang \& Zou, 2007), PFS (Wang et al., 2018), hesitant fuzzy sets (HFSs) (Zolfaghari \& Mousavi, 2018) and 2-tuple linguistic neutrosophic EDAS (Wang et al., 2019) are proposed to carry out risk assessment under such circumstances.

In this research, there are only a few studies in which MCDM methods are adopted for risk mitigation, which tends to optimize risk response or risk allocation. For example, TOPSIS and $\mathrm{K}$-nearest neighbor (KNN) techniques by Chen et al. (2012) and grey system theory by Chen et al. (2017) help construction material suppliers to handle the financial risk hedging with regard to the fluctuation in material prices and the variation in currency exchange rates or interest rates. It is worth mentioning that risk allocation can be considered as the nondeterministic polynomial (NP)-hardness problem. Therefore, GA (Fang et al., 2013; Alireza et al., 2014) and adaptive algorithm (Rahimi et al., 2018) are proposed to search the optimal solutions from a large number of candidates during a finite time.

\subsection{Sustainability/environment assessment (article number $=71)$}

\subsubsection{Sustainable performance assessment}

Nowadays, the concept of sustainability is generally acknowledged to be crucial in the construction industry (Ghoddousi et al., 2018). Relevant research mainly focuses on the identification of sustainable performance index and the implementation of sustainability assessment. Sustainability in the construction industry can be treated as the 
reconciliation of economic, environmental, and social dimensions (Torres-Machí et al., 2015). How to identify and balance the factors for each dimension becomes a major issue for decision makers (Cadena \& Magro, 2015). MADM methods are dominant in relevant research to achieve this purpose. For example, interval-valued fuzzy set (Chen et al., 2015), weighted aggregated sum product assessment (WASPAS) (Gholipour et al., 2018), and fuzzyDEMATEL-ANP approaches (Mavi \& Standing, 2018) are employed to establish the sustainable performance index or sustainable assessment criteria. On the other hand, construction researchers apply MADM methods to assess the sustainable performance of construction projects or measure the improvement of construction sustainability, which can be seen from Antuchevičiene et al. (2010) for revitalizing old buildings and Tan et al. (2014) for reducing construction wastes and saving natural resources. Besides the MADM methods mentioned above, integrated value model for sustainable assessment (Modelo Integrado de Valor para una Evaluación Sostenible - MIVES) (Pons et al., 2016) and MADM method based on value function (Pons \& Aguado, 2012; Cuadrado et al., 2016) are also applied in the construction industry for sustainability assessment.

\subsubsection{Environmental impact assessment}

The construction industry accounts for a significant proportion of total resource and energy consumption. Therefore, it is necessary to access the environmental impact of construction projects and further achieve environmentally conscious construction by taking effective actions during construction projects (Liu et al., 2018). Based on generic frameworks for rating the environmental performance of buildings and projects, such as Building Research Establishment Environmental Assessment Method (BREEAM) in the UK, Leadership in Energy and Environmental Design (LEED) in the US and Green Star in Australia, localization and customization of assessment categories and criteria may be needed (Banani et al., 2016; Zarghami et al., 2018). MCDM methods, such as MAUT and TOPSIS (Seyis \& Ergen, 2017), DEA (Vyas \& Jha, 2017) and fuzzy-AHP (Zarghami et al., 2018) are often involved in the process of localization and customization. Since the measurement of life-cycle environmental impact focuses on the quantification of tangible and intangible factors, fuzzy logic, such as fuzzy-ANP (Ignatius et al., 2016), BIM-aided fuzzy-PROMETHEE (Chen \& Pan, 2016), and vague set technique (Liu et al., 2018) are utilized in the construction industry.

\subsection{Suitability of MCDM application in construction}

A comprehensive analysis of the application of MCDM methods in construction shows that relevant research can be divided into decision making problems with a limited number of alternatives and those with a much larger number of alternatives. As for decision making problems with a limited number of alternatives, such as contractor (subcontractor)/supplier selection and material/equipment selection, MADM methods are more suitable under such a circumstance. Fuzzy logic is extensively used to accurately reflect uncertain information. Construction researchers tend to apply advanced fuzzy methods or fuzzy methods that are combined with other MCDM methods to solve decision making problems more effectively. On the other hand, many decision making problems in construction with a much larger number of alternatives, such as layout/location selection, may be formulated as classical optimization problems that are purposed to obtain possible satisfactory solutions within practical time limits. MODM methods, especially single EMO methods and EMO methods that are combined with other MCDM techniques, gain growing popularity in this context.

\section{Challenges and future research directions}

\subsection{Challenges and knowledge gaps in construction}

According to the statistical analysis in Section 3 and the discussion in Section 4, this research finds some common challenges and knowledge gaps for the application of MCDM methods in construction. First of all, most of the reviewed studies have not taken the applicability of the model into account. This research reveals 29 single methods and 94 hybrid methods of MCDM. In fact, few reviewed studies have analyzed the potential requirements for using certain MCDM methods, such as the independence restriction of attributes, the amount and dimension of attributes, and the conversion of qualitative attributes. For example, VIKOR's attributes should be independent of each other. However, none of the 17 studies on VIKOR reviewed in this research discusses the independence of attributes. The ignorance of the above requirements may lead to the inapplicability of the model or even wrong decision making.

Secondly, most of the reviewed works have ignored the robustness of the model. Few construction researchers have noted the following two concerns for applying MCDM methods in construction: (1) there is a potential risk of rank reversal error on adding or removing decision alternatives (Nazari et al., 2017); and (2) the use of different MCDM methods (especially MADM methods) may lead to different ranking orders (Zolfaghari \& Mousavi, 2018). The two concerns reflect the rank reversal problem that is characterized by a change in the rank ordering of the preferability of alternatives when the chosen methods or the original alternatives change (Sałabun et al., 2016; Ziemba \& Wątróbski, 2016). The rank reversal problem is particularly true for AHP-related methods. Some other MCDM methods applied in construction (i.e. ANP, ELECTRE, TOPSIS, PROMETHEE, MAUT, etc.) also encounter the same obstacle. In reality, the overwhelming majority of construction studies have either neglected testing the problems and validating the results when decision alternatives change or avoided comparing the strengths and 
performance of different MCDM methods in ranking alternatives.

Thirdly, the uptake of new MCDM methods in constriction lags behind. An obvious lag between MCDM application in construction and that in general is identified when referring to the dendrogram of MADM (see Figure 1) and the dendrogram of MODM (see Figure 2). For example, the revised PROMETHEE-II methods based on Brans (1982) in general are still commonly utilized in construction in recent years, which can be seen from Cavalcante et al. (2017), Silva et al. (2017) and Wu et al. (2018a). On the other hand, NSGA-II proposed by Deb et al. (2002) in general is not widespread in construction until recently (Lin et al., 2016; Yang et al., 2017; Wu et al., 2018b). In other words, "postpone effect" exists in the application of MCDM methods in construction. It is found in this research that MCDM methods adopted in construction mostly combine antiquity and ease of application. AHP and fuzzy-AHP are still the most popular single method and hybrid method, respectively. By comparison, the newer and more advanced methods have not yet received enough attention and large-scale application in construction.

Fourthly, most reviewed publications have completed by the historical and static data. In reality, decision making environment and decision making data are not static. Instead, construction projects are managed under fastchanging conditions. However, working in a dynamic or predictable manner can be only seen from several publications in recent years, such as Zhang et al. (2019) that built a model based on interval-AHP and TOPSIS to identify the real-time safety risk of metro construction adjacent building, Latifi et al. (2019) that presented a framwork according to the game theory and MODM to danamically optimize low impact development practices for urban storm water management, and Chalekaee et al. (2019) that established a new hybrid model based on several MADM methods to adress the future constrution delay change response problem. Unfortunatelly, the vast majority of previous publicarions are purely structured on the historical and static basis. As a result, they lose the power in practice when making decisions.
Fifthly, little has been done for the scale problem in MCDM application in construction. The scale problem arises when adding criteria or alternatives cause a significant increase in both computational time and cost. It can be categorized into (1) a large number of criteria; (2) a large number of alternatives; and (3) a large number of both criteria and alternatives (Liu et al., 2015b). It is difficult for a single MCDM method to deal with the scale problem in large and complex situations. When the number of objectives is greater than 3 , the consumption of computational resources, especially computational time, will increase exponentially following the increase in the number of objectives. Such situations will intensify in the context of big data. The construction industry is entering an era of big data. The rapid development of digital technologies in construction, such as BIM and GIS, makes the acquisition and processing of big data easier and more accessible. It can also be found in this research that many construction studies have integrated BIM and GIS into MCDM methods, such as AHP (Ristić et al., 2018), TOPSIS (Marzouk \& Al Daour, 2018) and fuzzy DEMATEL (Gigović et al., 2017). However, the acquired data by BIM or GIS is not fully utilized due to the scale problem of these traditional MCDM methods. Therefore, the scale problem become one of the biggest challenges to the application of MCDM methods in construction.

\subsection{Future studies on MCDM methods in general}

MCDM in general has been developing with the emergence of different methods one after another. However, there are still some challenges that lie ahead (see Table 4). With regard to MADM methods, improving existing methods to make them more robust (see the conditions for robustness from Brauers and Zavadskas (2010)) demands future studies. New algorithms or frameworks should be proposed in the future for robustness improvement. In addition to robustness improvement, future research efforts should be made to address the impreciseness or uncertainty of information during decision making processes. Soft computing represented by fuzzy set, grey set and rough set has been increasingly adopted. Soft comput-

Table 4. The research challenges and future studies on MCDM methods

\begin{tabular}{|l|l|l|}
\hline \multirow{4}{*}{ MADM } & \multicolumn{1}{|c|}{ Research challenges } & \multicolumn{1}{|c|}{ Future studies } \\
\hline & Less robustness & New or advanced algorithm design \\
\cline { 2 - 3 } & Impreciseness or uncertainty of information & Soft computing \\
\cline { 2 - 3 } & Unstable situation & DMADM \\
\cline { 2 - 3 } & Future aspects of issues & PMADM \\
\cline { 2 - 3 } & Higher dimensionality & MADM based scenarios \\
\cline { 2 - 3 } MODM & Less robustness & New or advanced algorithm design \\
\cline { 2 - 3 } & Computationally expensive & Surrogate models \\
\hline \multirow{3}{*}{ DSS for MCDM } & $\begin{array}{l}\text { High volume, high velocity and high variety } \\
\text { of the information }\end{array}$ & $\begin{array}{l}\text { Interdisciplinary integration (MCDM methods } \\
\text { and other techniques) } \\
\text { Advanced DSS for MCDM }\end{array}$ \\
\hline
\end{tabular}


ing methods are good at dealing with complex problems, imitating the human mind. Their combination with other MCDM methods can be further foreseen. Moreover, most general MCDM methods reviewed in Sections 1.3 and 1.4 are structured for a stable environment (unlike completely "static" within construction studies, "stable" means that change may exist but is slow) and based on the historical data. In reality, most decisions need to be made dynamically and even predictably to meet decision making requirements. Therefore, dynamic MADM (DMADM) that focuses on an unstable situation and prospective MADM (PMADM) that works on future aspects of issues and their dimensions are expected for future studies. In particular, a promising study is developing the framework of MADM based scenarios that can be applied regarding future issues in the unpredictable situations.

As for MODM methods, it is found in this research that most existing works solely solve low-dimensional problems (i.e. limited number of decision space and less than three objectives). Therefore, new and advanced algorithms or frameworks are necessary to be developed, focusing on problems with higher dimensionality, such as a research on the new performance indicators for indicator-based EMO. Obviously, each MODM method has both strengths and weaknesses. Selecting an appropriate method to obtain the most robust solution is one of the difficulties for decision makers. New techniques, such as hyper-heuristics that attempts to find the right method or heuristic sequence in a given situation automatically, have drawn notable attention recently. Most existing MODM methods become struggling for solving certain real-world multi-objective optimization problems in which computational cost is unaffordable or even prohibitive. Therefore, a future research trend is to adopt surrogate models that can reduce the fitness function evaluations required to produce acceptable results, especially for the computation with EMO.

It is worth to mention that, to address the complex situations of MCDM problems in practice, one solution is interdisciplinary integration. The integration of MCDM methods with the techniques from different disciplines, such as automation technology, computer science and operational research, is expected to transform big data into actionable information and knowledge for MCDM methods in a timely manner. For example, AI represented by machine learning seeks to detect patterns from the historical data and make predictions according to the new data (Henrique et al., 2019). Some studies, such as Tulabandhula and Rudin (2014) and Kashyap (2017), have demonstrated the major contribution of AI algorithms to the improvement of the capability to handle large datasets of decision making. Another solution is the adoption of Decision Support System (DSS) for MCDM, especially in the context of big data characterized by high volume, high velocity and high variety of information. With the help of data management, visualization and web-based technologies, DSS could provide a useful platform or framework, handling big data and making existing MCDM methods well adapted to the complex situations of MCDM problems. In summary, interdisciplinary integration and advanced DSS (e.g. biometric and intelligent DSS) for MCDM problems indicate important research directions for the MCDM application in general (see Figures 1 and 2). More details can be found from Kaklauskas (2015) and Filip (2020).

\subsection{Future research directions for MCDM in construction}

Based on the identification of MCDM challenges in construction (see Section 5.1) and the analysis of future studies on MCDM methods in general (see Section 5.2), further research directions are discussed below for MCDM in construction. As mentioned above, little or no attention to the applicability of MCDM methods is the first and foremost challenge in construction. To address this challenge, construction researchers should take the requirements of the MCDM method itself into consideration. It is appropriate for them to make frameworks solid and complete. On the other hand, decision makers are encouraged to pay attention to the applicability of MCDM methods carefully so that they can have a good understanding of the preconditions for applying certain MCDM methods.

The robustness challenge can be addressed from both internal and external perspectives of MCDM methods. To solve the problems inherent within existing MCDM methods, such as the reversal problem that mainly stems from the difference between the scale used for pair-wise comparison of alternatives and the actual scale of measuring each criterion (Shapira \& Goldenberg, 2005), future researches can be pursued in the following three ways: (1) adopting absolute measurement of alternatives instead of relative measurement; (2) ensuring decision makers' understanding of pair-wise comparison; and (3) improving the aggregation procedure of existing preferences. It is also important for construction researchers to ensure that nonrobust results are not caused by "garbage in, garbage out".

"Postpone effect" is well known because construction lags behind in terms of MCDM research and application. Figures 1 and 2 show the evolutionary development of MADM and MODM, respectively. It is important for construction researchers and decision makers to embrace the cutting edge MCDM methods. Under the premise of equally applicable conditions, for example, BWM is superior to AHP and ANP (see Section 1.3.2) and NSGA III performs better than NSGA II (see Section 1.4.3). Another future effort lies in the application of soft computing techniques, especially the improved methods of fuzzy set, rough set and grey set and their combination with other advanced MCDM methods, to solve complicated problems of decision making in construction. When facing new certain MODM problems, it is also possible for construction researchers and decision makers to try hyper-heuristic and identify which heuristic method works more efficiently and effectively. 
The lack of real-time and dynamic analysis challenges MCDM application in construction. Construction researchers and decision makers should focus on DMADM, PMADM relevant methods and MADM based scenarios, to overcome the reliance on the historical and static data as a common weakness in construction. The highlight of real-time and dynamic analysis not only addresses the challenge of the historical and static data but also provides a solution to the challenge of the "postpone effect" because new and advanced techniques are introduced into decision making.

In order to deal with the scale problem, it is possible to pursue research on decomposition based EMO methods that transform original problems into several single-objective optimization problems and indicator-based EMO that does not have scalability limitations compared to conventional Pareto based EMO. For the high dimensional search space and expensive objective functions for realworld complicated construction problems, research attention can be paid to surrogate models for evaluating the fitness functions to save calculation costs. Other possible solutions are external, that is, making use of interdisciplinary integration and advanced DSS. For the former solution, the integration of MCDM methods and emerging techniques (e.g. AI) can process the large volume data in construction to a certain extent. For the latter solution, advanced DSS can assist MCDM methods to collect and handle the big data of construction projects more sufficiently, comprehensively and agilely. With regard to interdisciplinary integration and advanced DSS as new and promising areas, Pan and Zhang (2021) and Marcher et al. (2020) summarized the frontier and exploratory research in construction recently. In the future, more and closer attention should be given in construction to relevant research on interdisciplinary integration and advanced DSS for MCDM.

\section{Conclusions}

Decision making is a critical process to achieve success in any sectors, especially in a sector like construction that requires handling numerous information and knowledge. MCDM methods contribute to appropriate decision making in general as well as in construction. They can be divided into MADM and MODM methods. This research first analyzes the evolutionary development of MADM and MODM in the general sense. A total of 530 construction articles published between 2000 and 2019 are then reviewed using the proposed methodology of SLR. Based on the SLR, this research offers a systematic and thorough understanding of MCDM application in seven construction areas. It is found from the analysis of relevant literature that various MCDM methods have developed in recent years at a faster rate and meanwhile there is a tendency toward cross-integration, which allow construction to adapt itself to increasingly complex environments.

In this research, the results of the literature review show the ever-growing popularity of MADM methods since 2005. This is because, compared to MODM methods, MADM methods generally require a smaller amount of data to deal with decision making problems. As a result, it is more practicable and possible. According to existing studies, AHP and fuzzy logic are more commonly used for construction decision making problems than other single methods. On the other hand, fuzzy-AHP and fuzzyTOPSIS are two dominant hybrid methods. Compared to single methods, hybrid methods become more promising. It is found in this research that MCDM methods can be mainly applied in seven construction areas (namely seven major themes) for decision making problems, ranging from contractor (subcontractor) / staff / supplier selection to sustainability/environment assessment. The finding of this research implies the penetrating involvement of MCDM in almost every aspect of construction decision making.

The development of MCDM research in construction is never stopped. This study identifies the potential challenges of the current MCDM research in construction, including the applicability concern, robustness problem, postpone effect, dynamic and prospective challenge, and scale problem. Subsequently, it presents the future directions for MCDM research in a new era. The new MCDM methods, such as soft computing, AI and other modern techniques, are expected to play important roles in addressing the above challenges for decision making in construction. The ultimate reason is not only the advancement of MCDM methods but also the complexity of construction problems.

Overall, this research adds value to the body of MCDM knowledge in three ways:

- It reveals the evolutionary development of MADM and MODM methods by retroactively classifying and deeply investigating the mainstream methods. Compared to previous studies, it updates the body of MCDM knowledge and adds the latest and most significant methods to the dendrograms (see Figures 1 and 2).

- It proposes a novel methodology of SLR to objectively explore the progression of MCDM in construction. The bibliometric analysis and discussion further provide researchers and practitioners with an intuitive understanding of the MCDM application status in different key areas.

- For the application of MCDM methods in construction, this research identifies the challenges and knowledge gaps. It also highlights the future research directions accordingly. These can provide insights and inspirations to construction research and practice in the MCDM context.

The SLR methodology proposed in this research has some strengths: (1) it can provide an evidence-based review, which seeks to comprehensively cover the subject to explore the body of literature; (2) the exclusion procedure depending on statistical non-parametric test can produce unbiased results to the greatest extent; and (3) the theme identification based on content co-occurrence analysis can 
objectively permit the accurate assessment and identify the application status. However, this research has certain limitations. Firstly, the scope of MCDM methods included in this research is limited to the mainstream methods. Although a large number of MCDM methods have emerged in recent years, it is impossible for this research to cover every method. Noteworthily, it does not mean that the methods excluded in this research have no importance. Secondly, the articles are collected from the journals in the Web of Science during the period from 2000 to 2019. The articles published in non-SCIE and non-SSCI journals are excluded. Meanwhile, conference articles, books and dissertations are not considered in the literature sample. Finally, the majority of existing studies on DSS for MCDM in construction mainly focus on system frameworks rather than MCDM methods and therefore they are not reviewed in this research. Due to all these reasons, future research is recommended through the collection and review of relevant literature from a wider range.

\section{Acknowledgements}

The authors sincerely acknowledge the encouragement of Professor Edmundas Kazimieras Zavadskas in Vilnius Gediminas Technical University. Thanks should also be given to Professor Kao-Yi Shen in Chinese Culture University for his suggestions on the development of MADM and MODM dendrograms.

\section{Disclosure statement}

The authors would like to declare that they no competing financial, professional, or personal interests from other parties.

\section{References}

Abbasianjahromi, H., \& Rajaie, H. (2012). Developing a project portfolio selection model for contractor firms considering the risk factor. Journal of Civil Engineering and Management, 18(6), 879-889. https://doi.org/10.3846/13923730.2012.734856

Abbasianjahromi, H., Rajaie, H., \& Shakeri, E. (2013). A framework for subcontractor selection in the construction industry. Journal of Civil Engineering and Management, 19(2), 158-168. https://doi.org/10.3846/13923730.2012.743922

Adrian, A. M., Utamima, A., \& Wang, K.-J. (2015). A comparative study of GA, PSO and ACO for solving construction site layout optimization. KSCE Journal of Civil Engineering, 19(3), 520-527. https://doi.org/10.1007/s12205-013-1467-6

Afshari, A. R. (2015). Selection of construction project manager by using Delphi and fuzzy linguistic decision making. Journal of Intelligent \& Fuzzy Systems, 28(6), 2827-2838. https://doi.org/10.3233/IFS-151562

Afshari, A. R. (2017). Methods for selection of construction project manager: Case study. Journal of Construction Engineering and Management, 143(12), 06017003. https://doi.org/10.1061/(ASCE)CO.1943-7862.0001400

Al-Humaidi, H. M. (2016). Construction projects bid or not bid approach using the fuzzy technique for order preference by similarity FTOPSIS method. Journal of Construction Engi- neering and Management, 142(12), 4016068.

https://doi.org/10.1061/(ASCE)CO.1943-7862.0001180

Alireza, V., Mohammadreza, Y., Zin, R. M., Yahaya, N., \& Noor, N. M. (2014). An enhanced multi-objective optimization approach for risk allocation in public-private partnership projects: A case study of Malaysia. Canadian Journal of Civil Engineering, 41(2), 164-177.

https://doi.org/10.1139/cjce-2013-0342

Almeida-Dias, J., Figueira, J. R., \& Roy, B. (2010). Electre TriC: A multiple criteria sorting method based on characteristic reference actions. European Journal of Operational Research, 204(3), 565-580. https://doi.org/10.1016/j.ejor.2009.10.018

Almeida-Dias, J., Figueira, J. R., \& Roy, B. (2012). A multiple criteria sorting method where each category is characterized by several reference actions: The Electre Tri-nC method. European Journal of Operational Research, 217(3), 567-579. https://doi.org/10.1016/j.ejor.2011.09.047

An, X., Wang, Z., Li, H., \& Ding, J. (2018). Project delivery system selection with interval-valued intuitionistic fuzzy set group decision-making method. Group Decision and Negotiation, 27(4), 689-707. https://doi.org/10.1007/s10726-018-9581-y

Angilella, S., Greco, S., Lamantia, F., \& Matarazzo, B. (2004). Assessing non-additive utility for multicriteria decision aid. European Journal of Operational Research, 158(3), 734-744. https://doi.org/10.1016/S0377-2217(03)00388-6

Antuchevičienė, J., Zavadskas, E. K., \& Zakarevičius, A. (2010). Multiple criteria construction management decisions considering relations between criteria. Technological and Economic Development of Economy, 16(1), 109-125.

https://doi.org/10.3846/tede.2010.07

Ardeshir, A., Mohseni, N., Behzadian, K., \& Errington, M. (2014a). Selection of a bridge construction site using fuzzy analytical hierarchy process in geographic information system. Arabian Journal for Science and Engineering, 39(6), 4405-4420. https://doi.org/10.1007/s13369-014-1070-2

Ardeshir, A., Amiri, M., Ghasemi, Y., \& Errington, M. (2014b). Risk assessment of construction projects for water conveyance tunnels using fuzzy fault tree analysis. International Journal of Civil Engineering, 12(4), 396-412.

Atanassov, K. T. (1986). Intuitionistic fuzzy sets. Fuzzy Sets and Systems, 20(1), 87-96.

https://doi.org/10.1016/S0165-0114(86)80034-3

Atanassov, K., \& Gargov, G. (1989). Interval valued intuitionistic fuzzy sets. Fuzzy Sets and Systems, 31(3), 343-349. https://doi.org/10.1016/0165-0114(89)90205-4

Bakht, M. N., \& El-Diraby, T. E. (2015). Synthesis of decisionmaking research in construction. Journal of Construction Engineering and Management, 141(9), 4015027. https://doi.org/10.1061/(ASCE)CO.1943-7862.0000984

Bana e Costa, C. A., \& Vansnick, J. C. (1994). MACBETH: an interactive path towards the construction of cardinal value functions. International Transactions in Operational Research, $1(4), 489-500$.

https://doi.org/10.1111/j.1475-3995.1994.00325.x

Banani, R., Vandati, M. M., Shahrestani, M., \& ClementsCroome, D. (2016). The development of building assessment criteria framework for sustainable non-residential buildings in Saudi Arabia. Sustainable Cities and Society, 26, 289-305. https://doi.org/10.1016/j.scs.2016.07.007

Banker, R. D., Charnes, A., \& Cooper, W. W. (1984). Some models for estimating technical and scale inefficiencies in data envelopment analysis. Management Science, 30(9), 1078-1092. https://doi.org/10.1287/mnsc.30.9.1078 
Bellman, R. E., \& Zadeh, L. A. (1970). Decision-making in a fuzzy environment. Management Science, 17(4), 141-164. https://doi.org/10.1287/mnsc.17.4.B141

Bernoulli, D. (1738). Specimen theoriae novae de mensura sortis. Commentarri Academiae Scientiarum Imperialis Petropolitanae, 5, 175-192.

Bigaret, S., Hodgett, R. E., Meyer, P., Mironova, T., \& Olteanu, A.-L. (2017). Supporting the multi-criteria decision aiding process: $\mathrm{R}$ and the MCDA package. EURO Journal on Decision Processes, 5(1-4), 169-194.

https://doi.org/10.1007/s40070-017-0064-1

Bouyssou, D., Marchant, T., Pirlot, M., Tsoukiàs, A., \& Vincke, P. (2006). Evaluation and dcision models with multiple criteria (Vol. 86). Kluwer Academic Publishers. https://doi.org/10.1007/0-387-31099-1

Brans, J. P. (1982). L’ingénierie de la décision élaboration d'instruments d'aide à la décision. In R. Nadeau \& M. Landry (Eds.), L'Aide à la décision: nature, instruments et perspectives d’avenir (pp. 183-214). Presses de l'Université Laval.

Brans, J. P., \& Mareschal, B. (1992). PROMETHEE V: MCDM problems with segmentation constraints. INFOR: Information Systems and Operational Research, 30(2), 85-96.

https://doi.org/10.1080/03155986.1992.11732186

Brans, J. P., \& Mareschal, B. (1995). The PROMETHEE VI procedure: how to differentiate hard from soft multicriteria problems. Journal of Decision Systems, 4(3), 213-223. https://doi.org/10.1080/12460125.1995.10511652

Brauers, W. K. M., \& Zavadskas, E. K. 2006. The MOORA method and its application to privatization in a transition economy. Control and Cybernetics, 35(2), 443-468.

Brauers, W. K. M., \& Zavadskas, E. K. 2010. Project management by MULTIMOORA as an instrument for transition economies. Technological and Economic Development of Economy, 16(1), 5-24. https://doi.org/10.3846/tede.2010.01

Buchanan, J. T. (1997). A naïve approach for solving MCDM problems: The GUESS method. Journal of the Operational Research Society, 48(2), 202-206.

https://doi.org/10.1057/palgrave.jors.2600349

Cadena, P. C. B., \& Magro, J. M. V. (2015). Setting the weights of sustainability criteria for the appraisal of transport projects. Transport, 30(3), 298-306.

https://doi.org/10.3846/16484142.2015.1086890

Cariaga, I., El-Diraby, T., \& Osman, H. (2007). Integrating value analysis and quality function deployment for evaluating design alternatives. Journal of Construction Engineering and Management, 133(10), 761-770.

https://doi.org/10.1061/(ASCE)0733-9364(2007)133:10(761)

Cascales, M. del S. G., Lozano, J. M. S., Arredondo, A. D. M., \& Corona, C. C. (2015). Soft computing applications for renewable energy and energy efficiency. IGI Global. https://doi.org/10.4018/978-1-4666-6631-3

Cavalcante, C. A. V., Alencar, M. H., \& Lopes, R. S. (2017). Multicriteria model to support maintenance planning in residential complexes under warranty. Journal of Construction Engineering and Management, 143(4), 4016110.

https://doi.org/10.1061/(ASCE)CO.1943-7862.0001250

Cebi, S., Celik, M., \& Kahraman, C. (2010). Structuring ship design project approval mechanism towards installation of operator-system interfaces via fuzzy axiomatic design principles. Information Sciences, 180(6), 886-895.

https://doi.org/10.1016/j.ins.2009.10.018

Cha, H., \& Lee, D. (2018). Determining value at risk for estimating renovation building projects by application of probability-based fuzzy set theory. Journal of Asian Architecture and
Building Engineering, 17(1), 63-70.

https://doi.org/10.3130/jaabe.17.63

Chalekaee, A., Turskis, Z., Khanzadi, M., Ghodrati Amiri, G., \& Keršuliene, V. (2019). A new hybrid MCDM model with grey numbers for the construction delay change response problem. Sustainability, 11(3), 776. https://doi.org/10.3390/su11030776

Charnes, A., Cooper, W. W., \& Ferguson, R. O. (1955). Optimal estimation of executive compensation by linear programming. Management Science, 1(2), 138-151.

https://doi.org/10.1287/mnsc.1.2.138

Charnes, A., Cooper, W. W., Golany, B., Seiford, L., \& Stutz, J. (1985). Foundations of data envelopment analysis for ParetoKoopmans efficient empirical production functions. Journal of Econometrics, 30(1-2), 91-107.

https://doi.org/10.1016/0304-4076(85)90133-2

Charnes, A., Cooper, W. W., \& Rhodes, E. (1978). Measuring the efficiency of decision making units. European Journal of Operational Research, 2(6), 429-444.

https://doi.org/10.1016/0377-2217(78)90138-8

Charnes, A., Cooper, W. W., Rousseau, J., \& Semple, J. (1987). Data envelopment analysis and axiomatic notions of efficiency and reference sets. University of Texas at Austin.

Chen, T.-Y. (2018). An interval-valued pythagorean fuzzy compromise approach with correlation-based closeness indices for multiple-criteria decision analysis of bridge construction methods. Complexity, Article ID 6463039.

https://doi.org/10.1155/2018/6463039

Chen, Y.-W., \& Hsieh, H.-E. (2006). Fuzzy multi-stage De-Novo programming problem. Applied Mathematics and Computation, 181(2), 1139-1147.

https://doi.org/10.1016/J.AMC.2006.01.083

Chen, S.-J., \& Hwang, C.-L. (1992). Fuzzy multiple attribute decision making - Methods and applications (Vol. 375). Springer. https://doi.org/10.1007/978-3-642-46768-4

Chen, L., \& Pan, W. (2016). BIM-aided variable fuzzy multicriteria decision making of low-carbon building measures selection. Sustainable Cities and Society, 27, 222-232. https://doi.org/10.1016/j.scs.2016.04.008

Chen, M.-F., \& Tzeng, G.-H. (2004). Combining grey relation and TOPSIS concepts for selecting an expatriate host country. Mathematical and Computer Modelling, 40(13), 1473-1490. https://doi.org/10.1016/j.mcm.2005.01.006

Chen, T.-T., \& Wu, T.-C. (2012). Construction project partnering using fuzzy based decision making methodology. Journal of the Chinese Institute of Engineers, 35(3), 269-284. https://doi.org/10.1080/02533839.2012.655462

Chen, Y., Okudan, G. E., \& Riley, D. R. (2010). Decision support for construction method selection in concrete buildings: Prefabrication adoption and optimization. Automation in Construction, 19(6), 665-675.

https://doi.org/10.1016/j.autcon.2010.02.011

Chen, Y., Liu, J., Li, B., \& Lin, B. (2011). Project delivery system selection of construction projects in China. Expert Systems with Applications, 38(5), 5456-5462.

https://doi.org/10.1016/j.eswa.2010.10.008

Chen, J.-H., Hsu, S.-C., Luo, Y.-H., \& Skibniewski, M. J. (2012). Knowledge management for risk hedging by construction material suppliers. Journal of Management in Engineering, 28(3), 273-280. https://doi.org/10.1061/(ASCE)ME.1943-5479.0000111

Chen, R.-H., Lin, Y., \& Tseng, M.-L. (2015). Multicriteria analysis of sustainable development indicators in the construction minerals industry in China. Resources Policy, 46, 123-133. https://doi.org/10.1016/j.resourpol.2014.10.012 
Chen, J.-H., Hsu, S.-C., Wang, R., \& Chou, H.-A. (2017). Improving hedging decisions for financial risks of construction material suppliers using grey system theory. Journal of Management in Engineering, 33(4), 04017016.

https://doi.org/10.1061/(ASCE)ME.1943-5479.0000531

Cheng, M.-Y., \& Lien, L.-C. (2012). Hybrid artificial intelligencebased PBA for benchmark functions and facility layout design optimization. Journal of Computing in Civil Engineering, 26(5), 612-624.

https://doi.org/10.1061/(ASCE)CP.1943-5487.0000163

Cheng, M.-Y., Tsai, H.-C., Ko, C.-H., \& Chang, W.-T. (2008). Evolutionary fuzzy neural inference system for decision making in geotechnical engineering. Journal of Computing in Civil Engineering, 22(4), 272-280.

https://doi.org/10.1061/(ASCE)0887-3801(2008)22:4(272)

Chien, K.-F., Wu, Z.-H., \& Huang, S.-C. (2014). Identifying and assessing critical risk factors for BIM projects: Empirical study. Automation in Construction, 45, 1-15.

https://doi.org/10.1016/j.autcon.2014.04.012

Choquet, G. (1954). Theory of capacities. Annales de l'institut Fourier, 5, 131-295. https://doi.org/10.5802/aif.53

Chou, J. S., Pham, A. D., \& Wang, H. (2013). Bidding strategy to support decision-making by integrating fuzzy AHP and regression-based simulation. Automation in Construction, 35, 517-527. https://doi.org/10.1016/j.autcon.2013.06.007

Cinelli, M., Coles, S. R., \& Kirwan, K. (2014). Analysis of the potentials of multi criteria decision analysis methods to conduct sustainability assessment. Ecological Indicators, 46, 138-148. https://doi.org/10.1016/j.ecolind.2014.06.011

Ćirović, G., \& Plamenac, D. (2006). Construction machines: Optimal choice of options using mathematical modelling. Kybernetes, 35(9), 1348-1368. https://doi.org/10.1108/03684920610662656

Cobo, M. J., López-Herrera, A. G., Herrera-Viedma, E., \& Herrera, F. (2011). Science mapping software tools: Review, analysis, and cooperative study among tools. Journal of the American Society for Information Science and Technology, 62(7), 1382-1402. https://doi.org/10.1002/asi.21525

Cohon, J. L., \& Marks, D. H. (1975). A review and evaluation of multiobjective programing techniques. Water Resources Research, 11(2), 208-220. https://doi.org/10.1029/WR011i002p00208

Cook, W. D., Tone, K., \& Zhu, J. (2014). Data envelopment analysis: Prior to choosing a model. Omega, 44, 1-4. https://doi.org/10.1016/j.omega.2013.09.004

Cuadrado, J., Zubizarreta, M., Rojí, E., Larrauri, M., \& Álvarez, I. (2016). Sustainability assessment methodology for industrial buildings: Three case studies. Civil Engineering and Environmental Systems, 33(2), 106-124.

https://doi.org/10.1080/10286608.2016.1148143

Cuong, B. C. (2014). Picture fuzzy sets. Journal of Computer Science and Cybernetics, 30(4), 409-420.

https://doi.org/10.15625/1813-9663/30/4/5032

Curiel-Esparza, J., \& Canto-Perello, J. (2013). Selecting utilities placement techniques in urban underground engineering. Archives of Civil and Mechanical Engineering, 13(2), 276-285. https://doi.org/10.1016/j.acme.2013.02.001

Das, I., \& Dennis, J. E. (1998). Normal-boundary intersection: A new method for generating the Pareto surface in nonlinear multicriteria optimization problems. SIAM Journal on Optimization, 8(3), 631-657.

https://doi.org/10.1137/S1052623496307510 de Azevedo, R. C., de Oliveira Lacerda, R. T., Ensslin, L., Jungles, A. E., \& Ensslin, S. R. (2013). Performance measurement to aid decision making in the budgeting process for apartment building construction: Case study using MCDA-C. Journal of Construction Engineering and Management, 139(2), 225-235. https://doi.org/10.1061/(ASCE)CO.1943-7862.0000587

Deb, K., \& Jain, H. (2014). An evolutionary many-objective optimization algorithm using reference-point-based nondominated sorting approach, Part I: Solving problems with box constraints. IEEE Transactions on Evolutionary Computation, 18(4), 577-601. https://doi.org/10.1109/TEVC.2013.2281535

Deb, K., Pratap, A., Agarwal, S., \& Meyarivan, T. (2002). A fast and elitist multiobjective genetic algorithm: NSGA-II. IEEE Transactions on Evolutionary Computation, 6(2), 182-197. https://doi.org/10.1109/4235.996017

Deng, J.-L. (1982). Control problems of grey systems. Systems \& Control Letters, 1(5), 288-294. https://doi.org/10.1016/S0167-6911(82)80025-X

Diao, X., Li, H., Zeng, S., Tam, V. W. Y., \& Guo, H. (2011). A Pareto multi-objective optimization approach for solving timecost-quality tradeoff problems. Technological and Economic Development of Economy, 17(1), 22-41.

https://doi.org/10.3846/13928619.2011.553988

Díaz-Cuevas, P., Camarillo-Naranjo, J. M., \& Pérez-Alcántara, J. P. (2018). Relational spatial database and multi-criteria decision methods for selecting optimum locations for photovoltaic power plants in the province of Seville (southern Spain). Clean Technologies and Environmental Policy, 20(8), 1889-1902. https://doi.org/10.1007/s10098-018-1587-2

Dikmen, I., Birgonul, M. T., \& Ozorhon, B. (2007). Project appraisal and selection using the analytic network process. $\mathrm{Ca}$ nadian Journal of Civil Engineering, 34(7), 786-792. https://doi.org/10.1139/L07-006

Dosal, E., Coronado, M., Munoz, I., Viguri, J. R., \& Andres, A. (2012). Application of multi-criteria decision-making tool to locate construction and demolition waste $(\mathrm{C} \& \mathrm{Dw})$ recycling facilities in a Northern Spanish region. Environmental Engineering and Management Journal, 11(3), 545-556.

https://doi.org/10.30638/eemj.2012.067

Doyle, J., \& Green, R. (1994). Efficiency and cross-efficiency in DEA: Derivations, meanings and uses. The Journal of the Operational Research Society, 45(5), 567-578.

https://doi.org/10.2307/2584392

Durach, C. F., Kembro, J., \& Wieland, A. (2017). A new paradigm for systematic literature reviews in supply chain management. Journal of Supply Chain Management, 53(4), 67-85. https://doi.org/10.1111/jscm.12145

Edwards, W. (1971). Social utilities. Engineering Economist, 6, 119-129.

Edwards, W., \& Barron, F. H. (1994). SMARTS and SMARTER: Improved simple methods for multiattribute utility measurement. Organizational Behavior and Human Decision Processes, 60(3), 306-325. https://doi.org/10.1006/OBHD.1994.1087

El-Mashaleh, M. S. (2013). Empirical framework for making the bid/no-bid decision. Journal of Management in Engineering, 29(3), 200-205.

https://doi.org/10.1061/(ASCE)ME.1943-5479.0000147

Emmerich, M., Beume, N., \& Naujoks, B. (2005). An EMO algorithm using the hypervolume measure as selection criterion. In C. A. Coello, A. Hernández Aguirre, \& E. Zitzler (Eds.), Lecture notes in computer science: Vol. 3410. Evolutionary multi-criterion optimization (pp. 62-76). Springer. https://doi.org/10.1007/978-3-540-31880-4_5 
Eshtehardian, E., Afshar, A., \& Abbasnia, R. (2009). Fuzzy-based MOGA approach to stochastic time-cost trade-off problem. Automation in Construction, 18(5), 692-701.

https://doi.org/10.1016/j.autcon.2009.02.001

Fang, C., Marle, F., Xie, M., \& Zio, E. (2013). An integrated framework for risk response planning under resource constraints in large engineering projects. IEEE Transactions on Engineering Management, 60(3), 627-639.

https://doi.org/10.1109/TEM.2013.2242078

Fare, R., Grosskopf, S., Fare, R., \& Grosskopf, S. (2000). Network DEA. Socio-Economic Planning Sciences, 34(1), 35-49. https://doi.org/10.1016/S0038-0121(99)00012-9

Figueira, J., Smet, Y. D., \& Brans, J. (2004). MCDA methods for sorting and clustering problems: Promethee TRI and Promethee CLUSTER.

Filip, F. G. (2020). DSS - A class of evolving information systems. In G. Dzemyda, J. Bernatavičienė, \& J. Kacprzyk (Eds.), Studies in computational intelligence: Vol. 869. Data science: New issues, challenges and applications (pp. 253-277). Springer, Cham. https://doi.org/10.1007/978-3-030-39250-5_14

Fishburn, P. C. (1974). Exceptional paper - Lexicographic orders, utilities and decision rules: A Survey. Management Science, 20(11), 1442-1471. https://doi.org/10.1287/mnsc.20.11.1442

Fontela, E., \& Gabus, A. (1972). World problems an invitation to further thought within the framework of DEMATEL. Geneva, Switzerland.

Fontela, E., \& Gabus, A. (1976). The DEMATEL observer. Geneva, Switzerland.

Fülöp, J. (2001). Introduction to decision making methods. Laboratory of Operations Research and Decision Systems. https://doi.org/10.1.1.86.6292

Gass, S., \& Saaty, T. (1955). The computational algorithm for the parametric objective function. Naval Research Logistics Quarterly, 2(1-2), 39-45. https://doi.org/10.1002/nav.3800020106

Ghapanchi, A. H., Tavana, M., Khakbaz, M. H., \& Low, G. (2012). A methodology for selecting portfolios of projects with interactions and under uncertainty. International Journal of Project Management, 30(7), 791-803.

https://doi.org/10.1016/j.ijproman.2012.01.012

Ghoddousi, P., Nasirzadeh, F., \& Hashemi, H. (2018). Evaluating highway construction projects' sustainability using a multicriteria group decision-making model based on bootstrap simulation. Journal of Construction Engineering and Management, 144(9), 4018092.

https://doi.org/10.1061/(ASCE)CO.1943-7862.0001514

Gholipour, Y., Hasheminasab, H., Kharrazi, M., \& Streimikis, J. (2018). Sustainability criteria assessment for life-cycle phases of petroleum refinery projects by MADM technique. E\&M Economics and Management, 21(3), 75-87. https://doi.org/10.15240/tul/001/2018-3-005

Giang, D. T. H., \& Pheng, L. S. (2011). Role of construction in economic development: Review of key concepts in the past 40 years. Habitat International, 35(1), 118-125. https://doi.org/10.1016/j.habitatint.2010.06.003

Gigović, L., Pamučar, D., Božanić, D., \& Ljubojević, S. (2017). Application of the GIS-DANP-MABAC multi-criteria model for selecting the location of wind farms: A case study of Vojvodina, Serbia. Renewable Energy, 103, 501-521.

https://doi.org/10.1016/j.renene.2016.11.057

Ginevičius, R. (2011). A new determining method for the criteria weights in multicriteria evaluation. International Journal of Information Technology \& Decision Making, 10(6), 1067-1095. https://doi.org/10.1142/S0219622011004713
Goldberg, D. E. (1989). Genetic algorithms in search, optimization, and machine learning (1st ed.). Addison-Wesley Longman Publishing Co., Inc.

Goldenberg, M., \& Shapira, A. (2007). Systematic evaluation of construction equipment alternatives: Case study. Journal of Construction Engineering and Management, 133(1), 72-85. https://doi.org/10.1061/(ASCE)0733-9364(2007)133:1(72)

Govindan, K., \& Jepsen, M. B. (2016). ELECTRE: A comprehensive literature review on methodologies and applications. European Journal of Operational Research, 250(1), 1-29. https://doi.org/10.1016/j.ejor.2015.07.019

Greco, S., Matarazzo, B., \& Słowiński, R. (2001). Rough sets theory for multicriteria decision analysis. European Journal of Operational Research, 129(1), 1-47.

https://doi.org/10.1016/s0377-2217(00)00167-3

Greco, S., Matarazzo, B., \& Słowiński, R. (2010). Dominancebased rough set approach to decision under uncertainty and time preference. Annals of Operations Research, 176(1), 4175. https://doi.org/10.1007/s10479-009-0566-8

Gu, X., Zhao, P., \& Wang, Y. (2014). Models for multiple attribute decision making based on the Einstein correlated aggregation operators with interval-valued intuitionistic fuzzy information. Journal of Intelligent \& Fuzzy Systems, 26(4), 2047-2055. https://doi.org/10.3233/IFS-130881

Gumusay, M. U., Koseoglu, G., \& Bakirman, T. (2016). An assessment of site suitability for marina construction in Istanbul, Turkey, using GIS and AHP multicriteria decision analysis. Environmental Monitoring and Assessment, 188(12), 677. https://doi.org/10.1007/s10661-016-5677-5

Gunduz, M., Nielsen, Y., \& Ozdemir, M. (2015). Fuzzy assessment model to estimate the probability of delay in Turkish construction projects. Journal of Management in Engineering, 31(4), 4014055.

https://doi.org/10.1061/(ASCE)ME.1943-5479.0000261

Haimes, Y. V, Lasdon, L. S., \& Wismer, D. A. (1971). On a bicriterion formulation of the problems of integrated system identification and system optimization. IEEE Transactions on Systems, Man, and Cybernetics, SMC-1(3), 296-297.

https://doi.org/10.1109/TSMC.1971.4308298

Hashiyama, T., Furuhashi, T., \& Uchikawa, Y. (1995). A study on varying degrees of attention in multi-attribute decision making processes. Journal of Japan Society for Fuzzy Theory and Systems, 7(4), 826-838. https://doi.org/10.3156/jfuzzy.7.4_826

Hasnain, M., Thaheem, M. J., \& Ullah, F. (2018). Best value contractor selection in road construction projects: ANP-based decision support system. International Journal of Civil Engineering, 16(6A), 695-714.

https://doi.org/10.1007/s40999-017-0199-2

Henrique, B. M., Sobreiro, V. A., \& Kimura, H. (2019). Literature review: Machine learning techniques applied to financial market prediction. Expert Systems with Applications, 124, 226-251. https://doi.org/10.1016/j.eswa.2019.01.012

Hsu, C. Y., Chen, K. T., \& Tzeng, G. H. (2007). FMCDM with fuzzy DEMATEL approach for customers' choice behavior model. International Journal of Fuzzy Systems, 9(4), 236-246. https://doi.org/10.30000/IJFS.200712.0007

Huang, J. J., \& Tzeng, G. H. (2014). New thinking of multi-objective programming with changeable space: In search of excellence. Technological and Economic Development of Economy, 20(2), 254-273. https://doi.org/10.3846/20294913.2013.860931

Hwang, C.-L., \& Masud, A. S. M. (1979). Lecture notes in economics and mathematical systems: Vol. 164. Multiple objective decision making - Methods and applications. A state-of-the-art survey. Springer. https://doi.org/10.1007/978-3-642-45511-7 
Hwang, C.-L., \& Yoon, K. (1981). Lecture notes in economics and mathematical systems: Vol. 186. Multiple attribute decision making. Methods and applications: A state-of-the-art survey. Springer. https://doi.org/10.1007/978-3-642-48318-9

Ignatius, J., Rahman, A., Yazdani, M., Šaparauskas, J., \& Haron, S. H. (2016). An integrated fuzzy ANP-QFD approach for green building assessment. Journal of Civil Engineering and Management, 22(4), 551-563.

https://doi.org/10.3846/13923730.2015.1120772

Ilce, A. C., \& Ozkaya, K. (2018). An integrated intelligent system for construction industry: a case study of raised floor material. Technological and Economic Development of Economy, 24(5), 1866-1884.

https://doi.org/10.3846/20294913.2017.1334242

Inyim, P., Rivera, J., \& Zhu, Y. (2015). Integration of building information modeling and economic and environmental impact analysis to support sustainable building design. Journal of Management in Engineering, 31(1), A4014002. https://doi.org/10.1061/(ASCE)ME.1943-5479.0000308

Iyer, K. C., \& Banerjee, P. S. (2016). Measuring and benchmarking managerial efficiency of project execution schedule performance. International Journal of Project Management, 34(2), 219-236. https://doi.org/10.1016/j.ijproman.2015.10.008

Jaskowski, P., Sobotka, A., \& Czarnigowska, A. (2014). Decision model for selecting supply sources of road construction aggregates. Engineering Economics, 25(1), 13-20.

https://doi.org/10.5755/j01.ee.25.1.3595

Jato-Espino, D., Castillo-Lopez, E., Rodriguez-Hernandez, J., \& Canteras-Jordana, J. C. (2014). A review of application of multi-criteria decision making methods in construction. Automation in Construction, 45, 151-162.

https://doi.org/10.1016/j.autcon.2014.05.013

Jessop, A. (2014). IMP: A decision aid for multiattribute evaluation using imprecise weight estimates. Omega, 49, 18-29. https://doi.org/10.1016/j.omega.2014.05.001

Kabak, M., Köse, E., Kırılmaz, O., \& Burmaoğlu, S. (2014). A fuzzy multi-criteria decision making approach to assess building energy performance. Energy and Buildings, 72, 382-389. https://doi.org/10.1016/j.enbuild.2013.12.059

Kahraman, C., \& Otay, İ. (Eds.). (2019). Studies in fuzziness and soft computing: Vol. 369. Fuzzy multi-criteria decision-making using neutrosophic sets. Springer International Publishing. https://doi.org/10.1007/978-3-030-00045-5

Kaklauskas, A. (2015). Biometric and intelligent decision making support. Springer. https://doi.org/10.1007/978-3-319-13659-2

Kangas, J., Kangas, A., Leskinen, P., \& Pykäläinen, J. (2001). MCDM methods in strategic planning of forestry on stateowned lands in Finland: Applications and experiences. Journal of Multi-Criteria Decision Analysis, 10(5), 257-271. https://doi.org/10.1002/mcda.306

KarimiAzari, A., Mousavi, N., Mousavi, S. F., \& Hosseini, S. (2011). Risk assessment model selection in construction industry. Expert Systems with Applications, 38(8), 9105-9111. https://doi.org/10.1016/j.eswa.2010.12.110

Kashyap, P. (2017). Machine learning for decision makers. Machine learning for decision makers. APRESS. https://doi.org/10.1007/978-1-4842-2988-0

Keeney, R. L. (1982). Decision analysis: An overview. Operations Research, 30, 803-838. https://doi.org/10.1287/opre.30.5.803

Keeney, R. L., \& Raiffa, H. (1972). A critique of formal analysis in public decision making. In A. W. Drake, R. L. Keeney, \& P. M. Morse (Eds.), Analysis of public systems (pp. 64-75). MIT Press.
Keeney, R. L., \& Raiffa, H. (1976). Decision analysis with multiple conflicting objectives. John Wiley.

Keršuliene, V., Zavadskas, E. K., \& Turskis, Z. (2010). Selection of rational dispute resolution method by applying new stepwise weight assessment ratio analysis (SWARA). Journal of Business Economics and Management, 11(2), 243-258. https://doi.org/10.3846/jbem.2010.12

Keshavarz Ghorabaee, M., Zavadskas, E. K., Olfat, L., \& Turskis, Z. (2015). Multi-criteria inventory classification using a new method of evaluation based on distance from average solution (EDAS). Informatica, 26(3), 435-451.

https://doi.org/10.15388/Informatica.2015.57

Keshavarz Ghorabaee, M., Zavadskas, E., Amiri, M., \& Turskis, Z. (2016). Extended EDAS method for fuzzy multi-criteria decision-making: An application to supplier selection. International Journal of Computers Communications \& Control, 11(3), 358-371. https://doi.org/10.15837/ijccc.2016.3.2557

Khanzadi, M., Nasirzadeh, F., Hassani, S. M. H., \& Mohtashemi, N. N. (2016). An integrated fuzzy multi-criteria group decision making approach for project delivery system selection. Scientia Iranica, 23(3), 802-814.

https://doi.org/10.24200/sci.2016.2160

Khoramshokooh, N., Veiskarami, M., Nikoo, M. R., \& Roshandeh, S. P. (2018). Multi-objective hydraulic optimization of diversion dam's cut-off. Water Resources Management, 32(11), 3723-3736. https://doi.org/10.1007/s11269-018-2015-4

Koopmans, T. C. (1951). Efficient allocation of resources. Econometrica: Journal of the Econometric Society, 19(4), 455-465. https://doi.org/10.2307/1907467

Korhonen, P. J., \& Laakso, J. (1985). On developing a visual interactive multiple criteria method: An outline. In Y. Y. Haimes \& V. Chankong (Eds.), Decision making with multiple objectives (pp. 272-281). Springer.

https://doi.org/10.1007/978-3-642-46536-9_18

Korhonen, P. J., \& Laakso, J. (1986). A visual interactive method for solving the multiple criteria problem. European Journal of Operational Research, 24(2), 277-287.

https://doi.org/10.1016/0377-2217(86)90050-0

Korhonen, P., \& Laakso, J. (1984). A visual interactive method for solving the multiple-criteria problem. In M. Grauer \& A. P. Wierzbicki (Eds.), Interactive decision analysis (pp. 146153). Springer. https://doi.org/10.1007/978-3-662-00184-4_17

Krylovas, A., Zavadskas, E. K., Kosareva, N., \& Dadelo, S. (2014). New KEMIRA method for determining criteria priority and weights in solving MCDM problem. International Journal of Information Technology \& Decision Making, 13(6), 1119-1133. https://doi.org/10.1142/s0219622014500825

Kuhn, H. W., \& Tucker, A. W. (1951). Nonlinear programming. In Proceedings of the Berkeley Symposium of Mathematical Statistics and Probability (pp. 481-491). University of California Press.

Kutlu Gündoğdu, F., \& Kahraman, C. (2019). Spherical fuzzy sets and spherical fuzzy TOPSIS method. Journal of Intelligent \& Fuzzy Systems, 36(1), 337-352. https://doi.org/10.3233/JIFS-181401

Kutlu Gündoğdu, F., \& Kahraman, C. (2020). A novel spherical fuzzy analytic hierarchy process and its renewable energy application. Soft Computing, 24(6), 4607-4621. https://doi.org/10.1007/s00500-019-04222-w

Latifi, M., Rakhshandehroo, G., Nikoo, M. R., \& Sadegh, M. (2019). A game theoretical low impact development optimization model for urban storm water management. Journal of Cleaner Production, 241, 118323.

https://doi.org/10.1016/j.jclepro.2019.118323 
Li, R. J., \& Lee, E. S. (1990). Multi-criteria de Novo programming with fuzzy parameters. Computers \& Mathematics with Applications, 19(5), 13-20.

https://doi.org/10.1016/0898-1221(90)90097-4

Li, F., Phoon, K. K., Du, X., \& Zhang, M. (2013). Improved AHP method and its application in risk identification. Journal of Construction Engineering and Management, 139(3), 312-320. https://doi.org/10.1061/(ASCE)CO.1943-7862.0000605

Li, H., Xiong, L., Liu, Y., \& Li, H. (2018). An effective genetic algorithm for the resource levelling problem with generalised precedence relations. International Journal of Production Research, 56(5), 2054-2075.

https://doi.org/10.1080/00207543.2017.1355120

Liang, H., Zhang, S., \& Su, Y. (2017a). Evaluating the efficiency of industrialization process in prefabricated residential buildings using a fuzzy multicriteria decision-making method. Mathematical Problems in Engineering, Article ID 6078490.

https://doi.org/10.1155/2017/6078490

Liang, R., Dong, Z., Sheng, Z., Wang, X., \& Wu, C. (2017b). Case study of selecting decision-making schemes in large-scale infrastructure projects. Journal of Infrastructure Systems, 23(4), 6017001.

https://doi.org/10.1061/(ASCE)IS.1943-555X.0000364

Lin, C.-C., Wang, W.-C., \& Yu, W.-D. (2008). Improving AHP for construction with an adaptive AHP approach (A3). Automation in Construction, 17(2), 180-187.

https://doi.org/10.1016/j.autcon.2007.03.004

Lin, Y.-H., Chen, Y.-P., Yang, M.-D., \& Su, T.-C. (2016). Multiobjective optimal design of sewerage rehabilitation by using the nondominated sorting genetic algorithm-II. Water Resources Management, 30(2), 487-503.

https://doi.org/10.1007/s11269-015-1173-x

Liou, J. J. H., \& Tzeng, G.-H. (2012). Comments on "Multiple criteria decision making (MCDM) methods in economics: An overview". Technological and Economic Development of Economy, 18(4), 672-695.

https://doi.org/10.3846/20294913.2012.753489

Liu, W., \& Sharp, J. (1999). DEA models via goal programming. In Data envelopment analysis in the service sector (pp. 79101). Deutscher Universitätsverlag.

https://doi.org/10.1007/978-3-663-08343-6_5

Liu, B., Huo, T., Shen, Q., Yang, Z., Meng, J., \& Xue, B. (2015a). Which owner characteristics are key factors affecting project delivery system decision making? Empirical analysis based on the rough set theory. Journal of Management in Engineering, 31(4), 5014018.

https://doi.org/10.1061/(ASCE)ME.1943-5479.0000298

Liu, J., Liu, P., Liu, S.-F., Zhou, X.-Z., \& Zhang, T. (2015b). A study of decision process in MCDM problems with large number of criteria. International Transactions in Operational Research, 22(2), 237-264. https://doi.org/10.1111/itor.12102

Liu, B., Huo, T., Meng, J., Gong, J., Shen, Q., \& Sun, T. (2016a). Identification of key contractor characteristic factors that affect project success under different project delivery systems: Empirical analysis based on a group of data from China. Journal of Management in Engineering, 32(1), 5015003.

https://doi.org/10.1061/(ASCE)ME.1943-5479.0000388

Liu, J. S., Lu, L. Y. Y., \& Lu, W. (2016b). Research fronts in data envelopment analysis. Omega, 58, 33-45.

https://doi.org/10.1016/j.omega.2015.04.004

Liu, Y., Li, F., Wang, Y., Yu, X., Yuan, J., \& Wang, Y. (2018). Assessing the environmental impact caused by power grid projects in high altitude areas based on BWM and vague sets techniques. Sustainability, 10(6), 1768.

https://doi.org/10.3390/su10061768
Loron, A. S., \& Loron, M. S. (2015). An integrated fuzzy analytic hierarchy process-fuzzy data envelopment analysis (FAHPFDEA) method for intelligent building assessment. Tehnicki Vjesnik-Technical Gazette, 22(2), 383-389.

https://doi.org/10.17559/TV-20140428223907

Lu, H., Wang, H., Xie, Y., \& Wang, X. (2018). Study on construction material allocation policies: A simulation optimization method. Automation in Construction, 90, 201-212.

https://doi.org/10.1016/j.autcon.2018.02.012

MacCrimmon, K. R. (1968). Decision making among multipleattribute alternatives: A survey and consolidated approach (Memorandum RM-4823-ARPA). The RAND corporation.

Malekmohammadi, B., \& Moghadam, N. T. (2018). Application of Bayesian networks in a hierarchical structure for environmental risk assessment: A case study of the Gabric Dam, Iran. Environmental Monitoring and Assessment, 190(5), 279. https://doi.org/10.1007/s10661-018-6609-3

Marcher, C., Giusti, A., \& Matt, D. T. (2020). Decision support in building construction: A systematic review of methods and application areas. Buildings, 10(10), 170. https://doi.org/10.3390/buildings 10100170

Marzouk, M., \& Al Daour, I. (2018). Planning labor evacuation for construction sites using BIM and agent-based simulation. Safety Science, 109, 174-185.

https://doi.org/10.1016/j.ssci.2018.04.023

Masoumi, I., Ahangari, K., \& Noorzad, A. (2018). Optimal monitoring instruments selection using innovative decision support system framework. Smart Structures and Systems, 21(1), 123-137. https://doi.org/10.12989/sss.2018.21.1.123

Mavi, R. K., \& Standing, C. (2018). Critical success factors of sustainable project management in construction: A fuzzy DEMATEL-ANP approach. Journal of Cleaner Production, 194, 751-765. https://doi.org/10.1016/j.jclepro.2018.05.120

Messac, A., Ismail-Yahaya, A., \& Mattson, C. A. (2003). The normalized normal constraint method for generating the Pareto frontier. Structural and Multidisciplinary Optimization, 25(2), 86-98. https://doi.org/10.1007/s00158-002-0276-1

Miandoabchi, E., Daneshzand, F., Zanjirani Farahani, R., \& Szeto, W. Y. (2015). Time-dependent discrete road network design with both tactical and strategic decisions. Journal of the Operational Research Society, 66(6), 894-913.

https://doi.org/10.1057/jors.2014.55

Michalewicz, Z. (1996). Genetic algorithms + Data structures = Evolution programs. Springer.

https://doi.org/10.1007/978-3-662-03315-9

Miettinen, K. (1998). Nonlinear multiobjective optimization. Kluwer Academic Publishers.

https://doi.org/10.1007/978-1-4615-5563-6

Miettinen, K., \& Mäkelä, M. M. (2006). Synchronous approach in interactive multiobjective optimization. European Journal of Operational Research, 170(3), 909-922.

https://doi.org/10.1016/j.ejor.2004.07.052

Migilinskas, D., Pavlovskis, M., Urba, I., \& Zigmund, V. (2017). Analysis of problems, consequences and solutions for BIM application in reconstruction projects. Journal of Civil Engineering and Management, 23(8), 1082-1090.

https://doi.org/10.3846/13923730.2017.1374304

Mikhailov, L., \& Singh, M. G. (2003). Fuzzy analytic network process and its application to the development of decision support systems. IEEE Transactions on Systems, Man and Cybernetics, Part C (Applications and Reviews), 33(1), 33-41. https://doi.org/10.1109/TSMCC.2003.809354

Mirahadi, F., \& Zayed, T. (2016). Simulation-based construction productivity forecast using neural-network-driven fuzzy rea- 
soning. Automation in Construction, 65, 102-115.

https://doi.org/10.1016/j.autcon.2015.12.021

Monghasemi, S., Nikoo, M. R., Fasaee, M. A. K., \& Adamowski, J. (2015). A novel multi criteria decision making model for optimizing time-cost-quality trade-off problems in construction projects. Expert Systems with Applications, 42(6), 3089-3104. https://doi.org/10.1016/j.eswa.2014.11.032

Nakayama, H. (1995). Aspiration level approach to interactive multi-objective programming and its applications. In P. M. Pardalos, Y. Siskos, \& C. Zopounidis (Eds.), Advances in multicriteria analysis (pp. 147-174). Springer.

https://doi.org/10.1007/978-1-4757-2383-0_10

Nazari, A., Vandadian, S., \& Abdirad, H. (2017). Fuzzy AHP model for prequalification of engineering consultants in the Iranian public procurement system. Journal of Management in Engineering, 33(2), 4016042.

https://doi.org/10.1061/(asce)me.1943-5479.0000489

Nieto-Morote, A., \& Ruz-Vila, F. (2012). A fuzzy multi-criteria decision-making model for construction contractor prequalification. Automation in Construction, 25, 8-19.

https://doi.org/10.1016/j.autcon.2012.04.004

Nikoo, M. R., Khorramshokouh, N., \& Monghasemi, S. (2015). Optimal design of detention rockfill dams using a simulation-based optimization approach with mixed sediment in the flow. Water Resources Management, 29(15), 5469-5488. https://doi.org/10.1007/s11269-015-1129-1

Ning, X., Ding, L. Y., Luo, H. B., \& Qi, S. J. (2016). A multi-attribute model for construction site layout using intuitionistic fuzzy logic. Automation in Construction, 72, 380-387. https://doi.org/10.1016/j.autcon.2016.09.008

Ning, X., Lam, K.-C., \& Lam, M. C.-K. (2011). A decision-making system for construction site layout planning. Automation in Construction, 20(4), 459-473.

https://doi.org/10.1016/j.autcon.2010.11.014

Opricovic, S. (1998). Multicriteria optimization of civil engineering systems [PhD thesis]. Faculty of Civil Engineering, University of Belgrade, Serbia.

Opricovic, S., \& Tzeng, G.-H. (2002). Multicriteria planning of post-earthquake sustainable reconstruction. Computer-Aided Civil and Infrastructure Engineering, 17, 211-220. https://doi.org/10.1111/1467-8667.00269

Opricovic, S., \& Tzeng, G.-H. (2007). Extended VIKOR method in comparison with outranking methods. European Journal of Operational Research, 178(2), 514-529.

https://doi.org/10.1016/j.ejor.2006.01.020

Ozcan-Deniz, G., Zhu, Y., \& Ceron, V. (2012). Time, cost and environmental impact analysis on construction operation optimization using genetic algorithms. Journal of Management in Engineering, 28(3), 265-272.

https://doi.org/10.1061/(ASCE)ME.1943-5479.0000098

Palha, R. P., de Almeida, A. T., \& Alencar, L. H. (2016). A model for sorting activities to be outsourced in civil construction based on ROR-UTADIS. Mathematical Problems in Engineering, Article ID 9236414. https://doi.org/10.1155/2016/9236414

Pan, Y., \& Zhang, L. (2021). Roles of artificial intelligence in construction engineering and management: A critical review and future trends. Automation in Construction, 122, 103517. https://doi.org/10.1016/j.autcon.2020.103517

Pawlak, Z. (1982). Rough sets. International Journal of Computer \& Information Sciences, 11(5), 341-356. https://doi.org/10.1007/BF01001956

Pawlak, Z., \& Słowiński, R. (1994). Rough set approach to multiattribute decision analysis. European Journal of Operational Research, 72(3), 443-459.

https://doi.org/10.1016/0377-2217(94)90415-4
Perny, P., \& Roy, B. (1992). The use of fuzzy outranking relations in preference modelling. Fuzzy Sets and Systems, 49(1), 33-53. https://doi.org/10.1016/0165-0114(92)90108-G

Plebankiewicz, E. (2014). Modelling decision-making processes in bidding procedures with the use of the fuzzy sets theory. International Journal of Strategic Property Management, 18(3), 307-316. https://doi.org/10.3846/1648715X.2014.943332

Polat, G., \& Bingol, B. N. (2017). Data envelopment analysis (DEA) approach for making the bid/no bid decision: A case study in a Turkish construction contracting company. Scientia Iranica, 24(2), 497-511.

https://doi.org/10.24200/sci.2017.2413

Pons, O., \& Aguado, A. (2012). Integrated value model for sustainable assessment applied to technologies used to build schools in Catalonia, Spain. Building and Environment, 53, 49-58. https://doi.org/10.1016/j.buildenv.2012.01.007

Pons, O., de la Fuente, A., \& Aguado, A. (2016). The use of MIVES as a sustainability assessment MCDM method for architecture and civil engineering applications. Sustainability, 8(5), 460. https://doi.org/10.3390/su8050460

Purshouse, R. C., Deb, K., Mansor, M. M., Mostaghim, S., \& Wang, R. (2014). A review of hybrid evolutionary multiple criteria decision making methods. In 2014 IEEE Congress on Evolutionary Computation (CEC), Beijing, China. https://doi.org/10.1109/CEC.2014.6900368

Radziszewska-Zielina, E. (2010). Methods for selecting the best partner construction enterprise in terms of partnering relations. Journal of Civil Engineering and Management, 16(4), 510-520. https://doi.org/10.3846/jcem.2010.57

Rahimi, Y., Tavakkoli-Moghaddam, R., Iranmanesh, S. H., \& Vaez-Alaei, M. (2018). Hybrid approach to construction project risk management with simultaneous FMEA/ISO 31000/ evolutionary algorithms: Empirical optimization study. Journal of Construction Engineering and Management, 144(6), 4018043. https://doi.org/10.1061/(ASCE)CO.1943-7862.0001486

Rahman, S., Odeyinka, H., Perera, S., \& Bi, Y. (2012). Productcost modelling approach for the development of a decision support system for optimal roofing material selection. Expert Systems with Applications, 39(8), 6857-6871. https://doi.org/10.1016/j.eswa.2012.01.010

RazaviAlavi, S., \& AbouRizk, S. (2017). Genetic algorithmsimulation framework for decision making in construction site layout planning. Journal of Construction Engineering and Management, 143(1), 4016084.

https://doi.org/10.1061/(ASCE)CO.1943-7862.0001213

Reizgevicius, M., Ustinovichius, L., Simanaviciene, R., Rasiulis, R., \& Peliksa, M. (2014). The evaluation and justification of the effectiveness of 4D CAD using multi-criteria analysis. Journal of Civil Engineering and Management, 20(6), 884-892. https://doi.org/10.3846/13923730.2014.978362

Rezaei, J. (2015). Best-worst multi-criteria decision-making method. Omega, 53, 49-57.

https://doi.org/10.1016/j.omega.2014.11.009

Ristić, V., Maksin, M., Nenković-Riznić, M., \& Basarić, J. (2018). Land-use evaluation for sustainable construction in a protected area: A case of Sara mountain national park. Journal of Environmental Management, 206, 430-445.

https://doi.org/10.1016/j.jenvman.2017.09.080

Roy, B. (1968). Classement et choix en présence de points de vue multiples. Revue Française d'informatique et de Recherche Opérationnelle, 2(8), 57-75.

https://doi.org/10.1051/ro/196802V100571 
Roy, B. (1971). Problems and methods with multiple objective functions. Mathematical Programming, 1(1), 239-266. https://doi.org/10.1007/BF01584088

Roy, B. (1976). From optimisation to multicriteria decision aid: Three main operational attitudes. In H. Thiriez \& S. Zionts (Eds.), Lecture notes in economics and mathematical systems (Operations research): Vol. 130. Multiple criteria decision making (pp. 1-34). Springer.

https://doi.org/10.1007/978-3-642-87563-2_1

Roy, B. (1977). Electre III, un algorithme de classement fondé sur une représentation floue des préférences en présence de critères multiples. Cahiers Du Centre détudes de Recherche Opérationnelle, 20(1), 3-24.

Roy, B. (1996). Multicriteria methodology for decision aiding (Vol. 12). Springer US. https://doi.org/10.1007/978-1-4757-2500-1

Roy, B. \& Vincke, P. (1981). Multicriteria analysis: Survey and new directions. European Journal of Operational Research, 8(3), 207-218. https://doi.org/10.1016/0377-2217(81)90168-5

Saaty, T. L. (1972). An eigenvalue allocation model for prioritization and planning (Working paper). Energy Management and Policy Center, University of Pennsylvania.

Saaty, T. L. (1992). A natural way to make momentous decisions. Journal of Scientific \& Industrial Research, 51(8-9), 69-81.

Saaty, T. L. (1996). Decision making with dependence and feedback: The Analytic Network Process. RWS Publications.

Sakawa, M., Inuiguchi, M., Sunada, H., \& Sawada, K. (1994). Fuzzy multiobjective combinatorial optimization through revised genetic algorithms. Journal of Japan Society for Fuzzy Theory and Systems, 6(1), 177-186. https://doi.org/10.3156/jfuzzy.6.1_177

Sakawa, M., Yumine, T., \& Nango, Y. (1984). Interactive fuzzy decisionmaking for multiobjective nonlinear programming problems. Electronics and Communications in Japan (Part I: Communications), 67(4), 31-38.

https://doi.org/10.1002/ecja.4400670405

Sałabun, W., Ziemba, P., \& Wątróbski, J. (2016). The rank reversals paradox in management decisions: The comparison of the AHP and COMET methods. In I. Czarnowski, A. M. Caballero, R. J. Howlett, \& L. C. Jain (Eds.), Smart innovation, systems and technologies: Vol. 56. Intelligent decision technologies (pp. 181-191). Springer International Publishing. https://doi.org/10.1007/978-3-319-39630-9_15

Salah, A., \& Moselhi, O. (2016). Risk identification and assessment for engineering procurement construction management projects using fuzzy set theory. Canadian Journal of Civil Engineering, 43(5), 429-442.

https://doi.org/10.1139/cjce-2015-0154

Samantra, C., Datta, S., \& Mahapatra, S. S. (2017). Fuzzy based risk assessment module for metropolitan construction project: An empirical study. Engineering Applications of Artificial Intelligence, 65, 449-464.

https://doi.org/10.1016/j.engappai.2017.04.019

Sasaki, M., Gen, M., \& Yamashiro, M. (1995). A method for solving fuzzy de novo programming problem by genetic algorithms. Computers \& Industrial Engineering, 29(1-4), 507-511. https://doi.org/10.1016/0360-8352(95)00125-K

Schaffer, J. D. (1984). Some experiments in machine learning using vector evaluated genetic algorithms (artificial intelligence, optimization, adaptation, pattern recognition). Vanderbilt University, Nashville, Tennessee.

Sedighi, M. (2016). Application of word co-occurrence analysis method in mapping of the scientific fields (case study: the field of Informetrics). Library Review, 65(1/2), 52-64.

https://doi.org/10.1108/LR-07-2015-0075
Seiford, L., \& Yu, P. L. (1979). Potential solutions of linear systems: The multi-criteria multiple constraint levels program. Journal of Mathematical Analysis and Applications, 69, 283303. https://doi.org/10.1016/0022-247X(79)90143-4

Sengupta, J. K. (1992a). A fuzzy systems approach in data envelopment analysis. Computers \& Mathematics with Applications, 24(8-9), 259-266.

https://doi.org/10.1016/0898-1221(92)90203-T

Sengupta, J. K. (1992b). Measuring efficiency by a fuzzy statistical approach. Fuzzy Sets and Systems, 46(1), 73-80.

https://doi.org/10.1016/0165-0114(92)90268-9

Sengupta, R. N., Gupta, A., \& Dutta, J. (2017). Decision sciences: theory and practice. CPC Press.

https://doi.org/10.1201/9781315183176

Seth, D., Nemani, V. S. R. K., Pokharel, S., \& Al Sayed, A. Y. (2018). Impact of competitive conditions on supplier evaluation: A construction supply chain case study. Production Planning \& Control, 29(3), 217-235.

https://doi.org/10.1080/09537287.2017.1407971

Seyis, S., \& Ergen, E. (2017). A decision making support tool for selecting green building certification credits based on project delivery attributes. Building and Environment, 126, 107-118. https://doi.org/10.1016/j.buildenv.2017.09.028

Shahhosseini, V., \& Sebt, M. H. (2011). Competency-based selection and assignment of human resources to construction projects. Scientia Iranica, 18(2), 163-180.

https://doi.org/10.1016/j.scient.2011.03.026

Shapira, A., \& Goldenberg, M. (2005). AHP-based equipment selection model for construction projects. Journal of Construction Engineering and Management, 131(12), 1263-1273. https://doi.org/10.1061/(ASCE)0733-9364(2005)131:12(1263)

Shi, H., Yin, H., \& Wei, L. (2016). A dynamic novel approach for bid/no-bid decision-making. SpringerPlus, 5(1), 1589.

https://doi.org/10.1186/s40064-016-3230-1

Shi, Y., \& Liu, Y.-H. (1993). Fuzzy potential solutions in multicriteria and multi-constraint level linear programming problems. Fuzzy Sets and Systems, 60(2), 163-179. https://doi.org/10.1016/0165-0114(93)90344-H

Sierra, L. A., Yepes, V., \& Pellicer, E. (2018). A review of multicriteria assessment of the social sustainability of infrastructures. Journal of Cleaner Production, 187, 496-513. https://doi.org/10.1016/j.jclepro.2018.03.022

Silva, M. M., Hipel, K. W., Kilgour, D. M., \& Cabral Seixas Costa, A. P. (2017). Urban planning in Recife, Brazil: Evidence from a conflict analysis on the new Recife project. Journal of Urban Planning and Development, 143(3), 05017007-1. https://doi.org/10.1061/(ASCE)UP.1943-5444.0000391

Simar, L., \& Wilson, P. W. (2000). Statistical inference in nonparametric frontier models: The state of the art. Journal of Productivity Analysis, 13(1), 49-78. https://doi.org/10.1023/A:1007864806704

Sitorus, F., Cilliers, J. J., \& Brito-Parada, P. R. (2019). Multi-criteria decision making for the choice problem in mining and mineral processing: Applications and trends. Expert Systems with Applications, 121, 393-417.

https://doi.org/10.1016/j.eswa.2018.12.001

Smarandache, F. (1998). A unifying field in logics: Neutrosophic logic. Neutrosophy, neutrosophic set, neutrosophic probability. American Research Press.

Stewart, T. J. (1996). Relationships between data envelopment analysis and multicriteria decision analysis. Journal of the $O p$ erational Research Society, 47(5), 654.

https://doi.org/10.2307/3010016 
Sugeno, M. (1974). Theory of fuzzy integrals and its applications. Tokyo Institute of Technology.

Tan, Y., Shen, L., \& Langston, C. (2014). A fuzzy approach for adaptive reuse selection of industrial buildings in Hong Kong. International Journal of Strategic Property Management, 18(1), 66-76. https://doi.org/10.3846/1648715X.2013.864718

Taylan, O., Bafail, A. O., Abdulaal, R. M. S., \& Kabli, M. R. (2014). Construction projects selection and risk assessment by fuzzy AHP and fuzzy TOPSIS methodologies. Applied Soft Computing, 17, 105-116. https://doi.org/10.1016/j.asoc.2014.01.003

Thomé, A. M. T., Scavarda, L. F., \& Scavarda, A. J. (2016). Conducting systematic literature review in operations management. Production Planning \& Control, 27(5), 408-420. https://doi.org/10.1080/09537287.2015.1129464

Tiwari, V., Jain, P. K., \& Tandon, P. (2017). A bijective soft set theoretic approach for concept selection in design process. Journal of Engineering Design, 28(2), 100-117. https://doi.org/10.1080/09544828.2016.1274718

Tone, K., \& Tsutsui, M. (2010). Dynamic DEA: A slacks-based measure approach. Omega, 38(3-4), 145-156. https://doi.org/10.1016/j.omega.2009.07.003

Torra, V., \& Narukawa, Y. (2009). On hesitant fuzzy sets and decision. In 2009 IEEE International Conference on Fuzzy Systems (pp. 1378-1382).

https://doi.org/10.1109/FUZZY.2009.5276884

Torres-Machí, C., Chamorro, A., Pellicer, E., Yepes, V., \& Videla, C. (2015). Sustainable pavement management: Integrating economic, technical and environmental aspects in decision making. Transportation Research Record: Journal of the Transportation Research Board, 2523(1), 56-63.

https://doi.org/10.3141/2523-07

Tranfield, D., Denyer, D., \& Smart, P. (2003). Towards a methodology for developing evidence-informed management knowledge by means of systematic review. British Journal of Management, 14(3), 207-222.

https://doi.org/10.1111/1467-8551.00375

Triantaphyllou, E. (2000). Multi-criteria decision making methods: A comparative study (Vol. 44). Springer US. https://doi.org/10.1007/978-1-4757-3157-6

Triantaphyllou, E., \& Lin, C.-T. (1996). Development and evaluation of five fuzzy multiattribute decision-making methods. International Journal of Approximate Reasoning, 14(4), 281-310. https://doi.org/10.1016/0888-613X(95)00119-2

Tsolas, I. E. (2013). Construction project monitoring by means of RAM-based composite indicators. Journal of the Operational Research Society, 64(8), 1291-1297. https://doi.org/10.1057/jors.2012.147

Tsoukiàs, A. (2007). On the concept of decision aiding process: An operational perspective. Annals of Operations Research, 154(1), 3-27. https://doi.org/10.1007/s10479-007-0187-Z

Tulabandhula, T., \& Rudin, C. (2014). On combining machine learning with decision making. Machine Learning, 97(1-2), 33-64. https://doi.org/10.1007/s10994-014-5459-7

Turskis, Z., \& Zavadskas, E. K. (2010). A new fuzzy additive ratio assessment method (ARAS-F). Case study: The analysis of fuzzy multiple criteria in order to select the logistic centers location. Transport, 25(4), 423-432.

https://doi.org/10.3846/transport.2010.52

Turskis, Z., Zavadskas, E. K., \& Kutut, V. (2013). A model based on ARAS-G and AHP methods for multiple criteria prioritizing of heritage value. International Journal of Information Technology \& Decision Making, 12(1), 45-73. https://doi.org/10.1142/S021962201350003X
Tzeng, G.-H., \& Shen, K.-Y. (2017). New concepts and trends of hybrid multiple criteria decision making (1st ed.). CRC Press. https://doi.org/10.1201/9781315166650

Tzeng, G., \& Tasur, S. (1994). The multiple criteria evaluation of grey relation model. The Journal of Grey System, 6(2), 87-108.

van Eck, N. J., \& Waltman, L. (2010). Software survey: VOSviewer, a computer program for bibliometric mapping. Scientometrics, 84(2), 523-538.

https://doi.org/10.1007/s11192-009-0146-3

van Laarhoven, P. J. M., \& Pedrycz, W. (1983). A fuzzy extension of Saaty's priority theory. Fuzzy Sets and Systems, 11(1-3), 229-241. https://doi.org/10.1016/S0165-0114(83)80082-7

Velasquez, M., \& Hester, P. T. (2013). An analysis of multi-criteria decision making methods. International Journal of Operations Research, 10(2), 56-66.

von Neumann, J., \& Morgenstern, O. (1947). Theory of games and economic behavior (2nd revised ed.). Princeton University Press.

Vyas, G. S., \& Jha, K. N. (2017). Benchmarking green building attributes to achieve cost effectiveness using a data envelopment analysis. Sustainable Cities and Society, 28, 127-134. https://doi.org/10.1016/j.scs.2016.08.028

Wan, S.-P., Wang, F., \& Dong, J.-Y. (2016). A preference degree for intuitionistic fuzzy values and application to multi-attribute group decision making. Information Sciences, 370-371, 127-146. https://doi.org/10.1016/j.ins.2016.07.013

Wang, L., Zhang, H., Wang, J., \& Li, L. (2018). Picture fuzzy normalized projection-based VIKOR method for the risk evaluation of construction project. Applied Soft Computing, 64, 216-226. https://doi.org/10.1016/j.asoc.2017.12.014

Wang, P., Wang, J., \& Wei, G. (2019). EDAS method for multiple criteria group decision making under 2-tuple linguistic neutrosophic enviroment. Journal of Intelligent \& Fuzzy Systems, 37(2), 1597-1608. https://doi.org/10.3233/JIFS-179223

Wierzbicki, A. P. (1982). A mathematical basis for satisficing decision making. Mathematical Modelling, 3(5), 391-405. https://doi.org/10.1016/0270-0255(82)90038-0

Wierzbicki, A. P. (1986). On the completeness and constructiveness of parametric characterizations to vector optimization problems. Operations Research Spektrum, 8(2), 73-87. https://doi.org/10.1007/BF01719738

Wu, W.-W. (2008). Choosing knowledge management strategies by using a combined ANP and DEMATEL approach. Expert Systems with Applications, 35(3), 828-835. https://doi.org/10.1016/j.eswa.2007.07.025

Wu, C., \& Barnes, D. (2016). An integrated model for green partner selection and supply chain construction. Journal of Cleaner Production, 112, 2114-2132. https://doi.org/10.1016/j.jclepro.2015.02.023

Wu, W., Guo, J., Li, J., Hou, H., Meng, Q., \& Wang, W. (2018a). A multi-objective optimization design method in zero energy building study: A case study concerning small mass buildings in cold district of China. Energy and Buildings, 158, 16131624. https://doi.org/10.1016/j.enbuild.2017.10.102

Wu, Y., Wang, J., Hu, Y., Ke, Y., \& Li, L. (2018b). An extended TODIM-PROMETHEE method for waste-to-energy plant site selection based on sustainability perspective. Energy, 156, 1-16. https://doi.org/10.1016/j.energy.2018.05.087

$\mathrm{Xu}$, J.-P. (1993). The grey hierarchy decision making. Journal of Grey Systems, 5(1), 35-44.

$\mathrm{Xu}$, J., Liu, Q. \& Lei, X. (2016). A fuzzy multi-objective model and application for the discrete dynamic temporary facilities location planning problem. Journal of Civil Engineering and Management, 22(3), 357-372.

https://doi.org/10.3846/13923730.2014.897974 
Xu, X. (2001). The SIR method: A superiority and inferiority ranking method for multiple criteria decision making. European Journal of Operational Research, 131(3), 587-602. https://doi.org/10.1016/S0377-2217(00)00101-6

Yan, M.-R., Pong, C.-S., \& Lo, W. (2011). Utility-based multicriteria model for evaluating BOT projects. Technological and Economic Development of Economy, 17(2), 207-218. https://doi.org/10.3846/16111699.2011.573281

Yang, Y.-P. O., Shieh, H.-M., Leu1, J.-D., \& Tzeng, G.-H. (2008). A novel hybrid MCDM model combined with DEMATEL and ANP with applications. International Journal of Operations Research, 5(3), 160-168.

Yang, M.-D., Lin, M.-D., Lin, Y.-H., \& Tsai, K.-T. (2017). Multiobjective optimization design of green building envelope material using a non-dominated sorting genetic algorithm. Applied Thermal Engineering, 111, 1255-1264. https://doi.org/10.1016/j.applthermaleng.2016.01.015

Yazdani-Chamzini, A., \& Yakhchali, S. H. (2012). Tunnel boring machine (TBM) selection using fuzzy multicriteria decision making methods. Tunnelling and Underground Space Technology, 30, 194-204. https://doi.org/10.1016/j.tust.2012.02.021

Yazdani, M., Wen, Z., Liao, H., Banaitis, A., \& Turskis, Z. (2019). A grey combined compromise solution (CoCoSo-G) method for supplier selection in construction management. Journal of Civil Engineering and Management, 25(8), 858-874.

https://doi.org/10.3846/jcem.2019.11309

Yepes, V., García-Segura, T., \& Moreno-Jiménez, J. M. (2015). A cognitive approach for the multi-objective optimization of RC structural problems. Archives of Civil and Mechanical Engineering, 15(4), 1024-1036.

https://doi.org/10.1016/j.acme.2015.05.001

Yu, P. L. (1973). A class of solutions for group decision problems. Management Science, 19(8), 936-946.

https://doi.org/10.1287/mnsc.19.8.936

Yu, W. (1992). ELECTRE TRI: Aspects méthodologiques et manuel d'utilisation. Université de Paris-Dauphine.

Zadeh, L. A. (1965). Fuzzy sets. Information and Control, 8(3), 338-353. https://doi.org/10.1016/S0019-9958(65)90241-X

Zadeh, L. A. (1975). The concept of a linguistic variable and its application to approximate reasoning I. Information Sciences, 8(3), 199-249. https://doi.org/10.1016/0020-0255(75)90036-5

Zahraie, B., \& Tavakolan, M. (2009). Stochastic time-cost-resource utilization optimization using nondominated sorting genetic algorithm and discrete fuzzy sets. Journal of Construction Engineering and Management, 135(11), 1162-1171. https://doi.org/10.1061/(ASCE)CO.1943-7862.0000092

Zarghami, E., Azemati, H., Fatourehchi, D., \& Karamloo, M. (2018). Customizing well-known sustainability assessment tools for Iranian residential buildings using fuzzy analytic hierarchy process. Building and Environment, 128, 107-128. https://doi.org/10.1016/j.buildenv.2017.11.032

Zavadskas, E. K., \& Antuchevičienè, J. (2007). Multiple criteria evaluation of rural building's regeneration alternatives. Building and Environment, 42(1), 436-451.

https://doi.org/10.1016/j.buildenv.2005.08.001

Zavadskas, E. K., \& Podvezko, V. (2016). Integrated determination of objective criteria weights in MCDM. International Journal of Information Technology \& Decision Making, 15(2), 267-283. https://doi.org/10.1142/s0219622016500036

Zavadskas, E. K., \& Turskis, Z. (2010). A New Additive Ratio Assessment (ARAS) method in multicriteria decision-making. Technological and Economic Development of Economy, 16(2), 159-172. https://doi.org/10.3846/tede.2010.10
Zavadskas, E. K., Kaklauskas, A., \& Sarka, V. (1994). The new method of multicriteria complex proportional assessment of projects. Technological and Economic Development of Economy, 1(3), 131-139.

Zavadskas, E. K., Kaklauskas, A., Turskis, Z., \& Tamošaitiene, J. (2008). Selection of the effective dwelling house walls by applying attributes values determined at intervals. Journal of Civil Engineering and Management, 14(2), 85-93. https://doi.org/10.3846/1392-3730.2008.14.3

Zavadskas, E. K., Turskis, Z., \& Antucheviciene, J. (2012a). Optimization of weighted aggregated sum product assessment. Elektronika ir elektrotechnika, 122(6), 3-6. https://doi.org/10.5755/j01.eee.122.6.1810

Zavadskas, E. K., Vainiunas, P., Turskis, Z., \& Tamosaitiene, J. (2012b). Multiple criteria decision support system for assessment of projects managers in construction. International Journal of Information Technology \& Decision Making, 11(2), 501-520. https://doi.org/10.1142/s0219622012400135

Zavadskas, E. K., Turskis, Z., \& Kildienè, S. (2014). State of art surveys of overviews on MCDM/MADM methods. Technological and Economic Development of Economy, 20(1), 165179. https://doi.org/10.3846/20294913.2014.892037

Zavadskas, E. K., Antuchevičienè, J., \& Kapliński, O. (2016a). Multi-criteria decision making in civil engineering. Part I - A state-of-the-art survey. Engineering Structures and Technologies, 7(3), 103-113.

https://doi.org/10.3846/2029882X.2015.1143204

Zavadskas, E. K., Antuchevičienè, J., \& Kaplinski, O. (2016b). Multi-criteria decision making in civil engineering. Part II Applications. Engineering Structures and Technologies, 7(4), 151-167. https://doi.org/10.3846/2029882X.2016.1139664

Zeleny, M. (1973). Compromise programming. In J. L. Cochrane \& M. Zeleny (Eds.), Multiple criteria decision making (pp. 262-301). University of South Carolina Press.

Zeleny, M. (1982). Multiple criteria decision making. McGrawHill.

Zeleny, M. (1986). Optimal system design with multiple criteria: De Novo programming approach. Engineering Costs and Production Economics, 10(1), 89-94. https://doi.org/10.1016/0167-188X(86)90029-7

Zeleny, M. (2011). Multiple criteria decision making (MCDM): From paradigm lost to paradigm regained? Journal of MultiCriteria Decision Analysis, 18(1-2), 77-89. https://doi.org/10.1002/mcda.473

Zhai, X., Wang, J., \& Chen, J. (2018). Parameter estimation method of mixture distribution for construction machinery. Mathematical Problems in Engineering, Article ID 3124048. https://doi.org/10.1155/2018/3124048

Zhang, G., \& Zou, P. X. (2007). Fuzzy analytical hierarchy process risk assessment approach for joint venture construction projects in China. Journal of Construction Engineering and Management, 133(10), 771-779. https://doi.org/10.1061/(ASCE)0733-9364(2007)133:10(771)

Zhang, S., Shang, C., Wang, C., Song, R., \& Wang, X. (2019). Real-time safety risk identification model during metro construction adjacent to buildings. Journal of Construction Engineering and Management, 145(6), 04019034. https://doi.org/10.1061/(ASCE)CO.1943-7862.0001657

Zhao, Z.-Y., Zhao, X.-J., Davidson, K., \& Zuo, J. (2012). A corporate social responsibility indicator system for construction enterprises. Journal of Cleaner Production, 29-30, 277-289. https://doi.org/10.1016/j.jclepro.2011.12.036

Ziemba, P., \& Wątróbski, J. (2016). Selected issues of rank reversal problem in ANP method. In K. Nermend, \& M. Łatuszyńska 
(Eds.), Selected issues in experimental economics. Springer proceedings in business and economics (pp. 203-225). Springer, Cham. https://doi.org/10.1007/978-3-319-28419-4_14

Zimmermann, H.-J. (1978). Fuzzy programming and linear programming with several objective functions. Fuzzy Sets and Systems, 1(1), 45-55.

https://doi.org/10.1016/0165-0114(78)90031-3

Zitzler, E., \& Künzli, S. (2004). Indicator-based selection in multiobjective search. In X. Yao et al. (Eds.), Lecture notes in computer science: Vol. 3242. Parallel problem solving from nature - PPSN VIII (pp. 832-842). Springer, Berlin, Heidelberg. https://doi.org/10.1007/978-3-540-30217-9_84

Zitzler, E., \& Thiele, L. (1999). Multiobjective evolutionary algorithms: a comparative case study and the strength Pareto approach. IEEE Transactions on Evolutionary Computation, 3(4), 257-271. https://doi.org/10.1109/4235.797969

Zolfaghari, S., \& Mousavi, S. M. (2018). Construction-project risk assessment by a new decision model based on De Novo multi-approaches analysis and hesitant fuzzy sets under uncertainty. Journal of Intelligent \& Fuzzy Systems, 35(1), 639-649. https://doi.org/10.3233/JIFS-162013

Zolfani, S. H., Rezaeiniya, N., Zavadskas, E. K., \& Turskis, Z. (2011). Forest roads locating based on AHP and Copras-G methods: An empirical study based on Iran. E\&M Economics and Management, 14(4), 6-21. 